\title{
Nucleo-cytoplasmic transport defects and protein aggregates in neurodegeneration
}

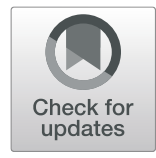

\author{
Giacomo Bitetto and Alessio Di Fonzo ${ }^{*}$ (i)
}

\begin{abstract}
In the ongoing process of uncovering molecular abnormalities in neurodegenerative diseases characterized by toxic protein aggregates, nucleo-cytoplasmic transport defects have an emerging role. Several pieces of evidence suggest a link between neuronal protein inclusions and nuclear pore complex (NPC) damage. These processes lead to oxidative stress, inefficient transcription, and aberrant DNA/RNA maintenance. The clinical and neuropathological spectrum of NPC defects is broad, ranging from physiological aging to a suite of neurodegenerative diseases. A better understanding of the shared pathways among these conditions may represent a significant step toward dissecting their underlying molecular mechanisms, opening the way to a real possibility of identifying common therapeutic targets.
\end{abstract}

Keywords: Aging, Neurodegeneration, Neurodegenerative disease, Nucleo-cytoplasmic transport, Nuclear pore complex, Protein aggregate

\section{Background}

Neuronal protein aggregates are a characteristic neuropathological hallmark of neurodegenerative disorders such as amyotrophic lateral sclerosis (ALS), frontotemporal dementia (FTD), Alzheimer's disease (AD), Huntington's disease (HD), polyglutamine expansion related ataxias, and Parkinson's disease (PD) [1]. One possible consequence of these aggregates is interference with the proper functioning of the highly conserved nucleo-cytoplasmic transport (NCT) mechanism in the cell, which ensures the transport of nucleic acids and proteins across the nuclear membrane. This pathway is fundamental for long-lived cells such as neurons [2, 3], and emerging evidence links damage to the nuclear membrane and nuclear pores to neurodegenerative diseases and physiological neuronal aging [4].

A properly functional NCT is fundamental for neurons to allow transcription factors to enter into the nucleus

\footnotetext{
* Correspondence: Alessio.difonzo@policlinico.mi.it

IRCCS Foundation Ca' Granda Ospedale Maggiore Policlinico, Dino Ferrari Center, Neuroscience Section, Department of Pathophysiology and Transplantation, University of Milan, Via Francesco Sforza 35, 20122 Milan, Italy
}

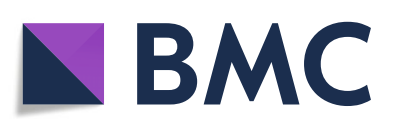

[5]. One essential NCT role is to activate regulatory elements necessary for adaptation and response to external stimuli, especially those implicated in neuronal plasticity [6]. Moreover, in non-dividing post-mitotic cells such as neurons, proteins involved in DNA maintenance and repair reach the nucleus through this mechanism $[7,8]$. In addition, all ribonucleic proteins involved in processes of RNA maturation, stability, splicing, and export require this transport for localization to the nucleus [9].

The cell relies on an essential, conserved, and dynamic structure called Nuclear Pore Complex (NPC) to accomplish a correct NCT [5]. Small molecules (molecular weight $<40 \mathrm{kDa}$, diameter $<5 \mathrm{~nm}$ ) can relatively freely diffuse through the NPC [5]. In contrast, higher molecularweight proteins depend on the highly regulated and very specific mechanisms of the NCT machinery [5].

NPCs are large cellular structures that span the nuclear envelope [10] and control exchanges between the cytoplasm and nucleus. The NPC is constituted by proteins collectively referred to as nucleoporins (Nups) [11] that have different roles in regulating NPC functions and transport of matter, energy, and information

(c) The Author(s). 2020 Open Access This article is licensed under a Creative Commons Attribution 4.0 International License, which permits use, sharing, adaptation, distribution and reproduction in any medium or format, as long as you give appropriate credit to the original author(s) and the source, provide a link to the Creative Commons licence, and indicate if changes were made. The images or other third party material in this article are included in the article's Creative Commons licence, unless indicated otherwise in a credit line to the material. If material is not included in the article's Creative Commons licence and your intended use is not permitted by statutory regulation or exceeds the permitted use, you will need to obtain permission directly from the copyright holder. To view a copy of this licence, visit http://creativecommons.org/licenses/by/4.0/ The Creative Commons Public Domain Dedication waiver (http://creativecommons.org/publicdomain/zero/1.0/) applies to the data made available in this article, unless otherwise stated in a credit line to the data. 
between the nucleus and cytoplasm [12]. In addition, the NPC is involved in cell cycle regulation, chromatin organization, and gene activation $[6,13]$.

Despite the relatively large size of NPCs, most proteins and RNAs cannot freely diffuse through them. Indeed, the passage through NPC is a highly coordinated and selective process, mediated by a family of soluble receptors called karyopherins (Kaps), also known as importins/ exportins [14]. The small Ras-related nuclear protein (Ran) plays a central role in this transport and regulates interactions between Kaps and their cargos on either side of the NPC [15]. Ran is the only known member of the Ras superfamily of small GTP-binding proteins that is localized principally inside the nucleus $[16,17]$. A gradient of RanGDP/GTP across the nuclear membrane is essential in establishing the directionality of the transport. To maintain the gradient, RanGTP is hydrolyzed to RanGDP on the cytoplasmic side and RanGDP is converted to RanGTP in the nucleus [17].

The nuclei of human cells have several thousand NPCs, with a structure that seems to have been highly conserved, underlining their importance for cells [18]. Nevertheless, despite this high degree of structural conservation of the NPC complex, two crucial time points in evolution from prokaryotes to humans have been suggested in NPC development, implying that the nuclear pore is still highly adaptive and flexible at the sequence level [19].

Neurons seem particularly sensitive to the damage of these structures, as demonstrated by the exclusively neurodegenerative consequence of many diseases due to damage of the NPC function and the NCT. So far, several reasons for this vulnerability have been studied. One clue is the inability of neurons to undergo mitosis, the usual process of cellular renewal [20]. Through DNA replication, cells maintain physiological protection of the genome from exogenous damages. To preserve genomic integrity, there are at least four active DNA repair pathways in nervous system each corresponding to a particular type of DNA lesions [21]. Genome instability can appear when the accumulation of DNA damage exceeds a neuron's repair capacity or the DNA repair machinery is defective [20]. Thus, transport across the nuclear membrane represents a unique possibility for neurons to guarantee DNA integrity, and genome instability is a major factor in neuronal aging [22, 23]. For example, somatic single nucleotide variants have been reported to be in excess in neurons from people affected by early-onset degeneration with DNA repair gene mutations [24].

Cellular oxidative stress is one of the primary sources of DNA damage, mostly in the brain due to its high demand for energy and increased radical oxygen species (ROS) formation [25]. This process, in addition to direct effects on DNA stability, is increasingly reported to affect NCT [26, 27]. At least four mechanisms have been associated with oxidative stress: reduced Ran GDP/GTP ratio, mislocalization of Nups, altered functions (binding, docking) of importins/exportins, and decreased integrity of the nuclear membrane [28].

RNA transport defects are an additional sign of neuronal sensitivity to NCT impairment, and of course, the export of RNAs from the nucleus to the cytoplasm is key to gene expression [29]. Moreover, a tRNA retrograde transport between cytoplasm and nucleus has recently been proposed as part of the cellular response to oxidative stress [30]. Among neurons, proper RNA shuttling function appears even more relevant for cells with a high transcriptional activity such as Purkinje cells and motor neurons [31-33]. All of these NCT defects that significantly affect DNA and RNA are related to aging and are even more relevant in neurodegeneration [26]. RNA-binding proteins mutated in specific neurodegenerative disorders (TDP-43, FUS, and hnRNPA1) can alter the dynamics of membrane-less organelles such as stress granules, or the more recently identified liquid droplets, and accelerate fibrillization in neurons, resulting in the formation of pathological amyloid-like fibrils that deposit in the cell bodies and neuropil [34-36].

Neurodegenerative disorders display a unique pathological hallmark arising from specific gene mutations. This hallmark is protein aggregates, which are known to damage NPCs [34, 37, 38], and evidence indicates that protein and RNA aggregates may interfere directly with specific Nups [34, 37]. In some neurons, Nups mislocalization and altered NPC function could lead to an even greater increase in aggregate accumulation and genome stress due to chromatin and DNA/RNA impairment [39, 40]. Further complicating this picture, the pathogenic process includes aberrant transcript maturation, transport, and translation [41] (Fig. 1).

The neuronal inclusions detected in neurodegenerative forms have been linked to deficient mechanisms of degradation, especially proteasomal and autophagy processes [42].

Whether the pathological cascade, starting from the formation of the aggregates and the damage of the NPC, to the enhanced fibrillation, may represent a common paradigm underlying different neurodegenerative diseases is still unknown.

In summary, several lines of evidences are emerging to suggest a link between the formation of neuronal aggregates and the structural and functional damages of the NPC, as well as the NCT pathways. However, it is not clear yet whether NCT dysfunction act as an upstream common pathogenetic mechanism in the neurodegenerative process or a downstream event triggered by specific pathological aggregates of different neurological disorders. To give an overview that may facilitate the design of future studies, we review here the most relevant 


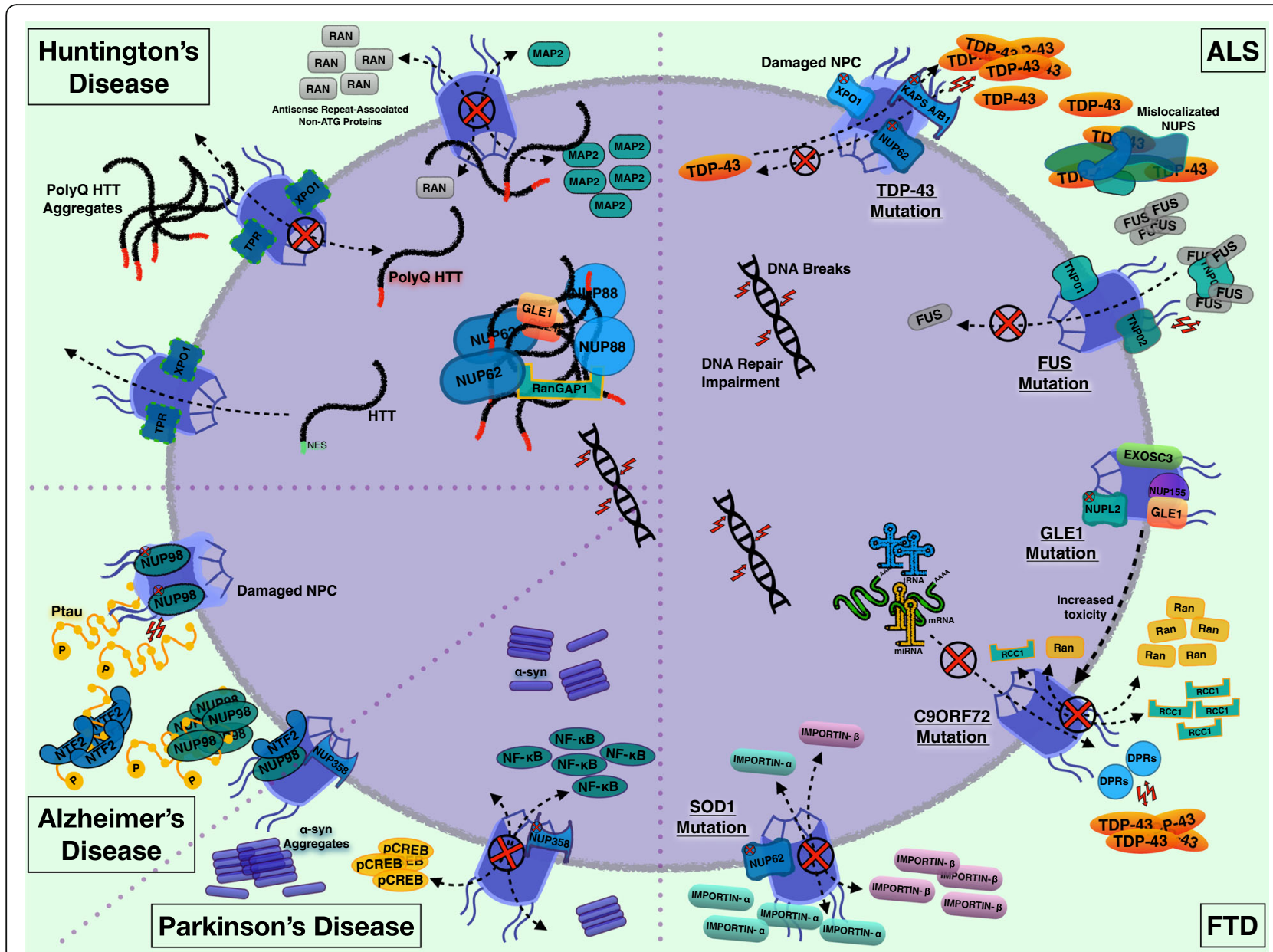

Fig. 1 Representation of the nucleus and NPCs with Nups, protein/RNA aggregates in several neurodegenerative diseases.

ALS/FTD:

- Damaged NPC and specific Nups involved in the presence of TDP-43 cytoplasmic aggregates and impaired TDP-43 nuclear import.

- Impaired FUS import in the presence of aggregates containing FUS with the importin TNPO1 or alone.

- Impaired RNA export in C9ORF72 mutations with DPRs and TDP-43 protein aggregates formation.

- Altered Ran and RCC1 nucleo-cytoplasmic distribution; C9ORF72 toxicity is increased by GLE1.

- EXOSC3 dysfunction.

- Altered distribution of importin- $\alpha$ and $-\beta$ in SOD1 mutation with Nup62 impairment.

HD: HTT physiological transport across the NPC through the interaction of NES with TPR and XPO1. Aberrant shuttling of RAN proteins and MAP2 due to PolyQ HTT affecting the NPC. Intranuclear aggregates of PolyQ HTT sequestering Nup62, Nup88, GLE1, and RanGAP1.

AD: Phospho-tau aggregates induce NPC damage and accumulation of NTF2 and Nup98 in the cytoplasm; Nup98 loss, in turn, may facilitate tau aggregation.

PD: Cytoplasmic aggregates and intranuclear alpha-synuclein in Parkinson's disease; pCREB aggregates and nuclear accumulation of NFkB are associated with

NPC and Nup358 defects in PD

pieces of evidence of NCT impairment in neurodegeneration. We explore several neurodegenerative diseases, their pathogenic mechanisms, and genetic causes, highlighting the role of NPC and NCT as key factors in modulating the neurodegenerative process and also physiological aging.

\section{Main text}

NPC structure and function

The nucleus is the central and distinguishing organelle of eukaryotic cells, encompassed by a double membrane dynamic structure called the nuclear envelope [43]. This envelope consists of an outer membrane that is directly continuous with the rough endoplasmic reticulum and an inner membrane that contains a specific set of nuclear envelope transmembrane proteins [44]. Internal to the nuclear envelope is the nuclear lamina, a dense fibrillar network of intermediate filaments that surrounds the cellular genome [45]. These structures guarantee the specific eukaryotic compartmentalization that segregates the DNA from the cytoplasm. Accomplishing this function requires an accurate system providing 
proper communication and molecular transport among the different cellular compartments [46, 47], which is the role of NPCs.

Vertebrate NPCs are $\sim 70 \mathrm{~nm}$ protein channels spanning the nuclear envelope, with a cylindrical scaffold of $\sim 125 \mathrm{~nm}$ and internal diameter of $\sim 40 \mathrm{~nm}$ [48]. The channel connects the nucleus and the cytoplasm. NPC is the largest cellular protein structure at $\sim 125 \mathrm{MDa}$ [12], consisting of more than 30 different proteins called Nups $[49,50]$. When assembled, they form a cytoplasmic ring, spoke ring, and nuclear ring [12]. Eight filaments are attached to the rings at the nuclear and cytoplasmic sides [51-53]. On the nuclear side, $\sim 50 \mathrm{~nm}$ filaments are connected in a basket-like structure, while on the cytoplasmic side, the filaments are linked to the Nup214 complex $[9,48,54,55]$.

The NPC has a complex and highly regulated function, and most of the specific roles of single Nups are not well known. What is known is that a particular group of Nups in the central channel is fundamental to the selective barrier and substrate-specific transport role of NPCs $[56,57]$. These Nups are characterized by phenylalanine-glycine (FG) domains and are anchored to the core scaffold through linker Nups [58]. Moreover, several Nups seem to exhibit a certain level of redundancy and functional overlap, forming an extremely dynamic barrier $[56,57]$.

With their intrinsic disordered FG domains, FG Nups form a dynamic filter that prevents passive diffusion of molecules through the NPC and allows for regulated transport of larger protein complexes of up to $40 \mathrm{~nm}[59,60]$. A single pore can contain $6 \mathrm{MDa}$ of FG repeats, providing docking sites for import and export nuclear transport receptors (NTRs) that are crucial for selective passage [54, 61]. Molecules passing from the cytoplasm to the nucleus and vice versa must bear specific signaling sequences to interact with the NPC [54]. NPCs do not change from a defined "closed" to an "open" state during this passage, and the bond with the substrates consists of multiple weak contacts between the NTRs and the FG Nups assembly [58, 62, 63].

Among the many different NTRs, the largest group is the highly conserved family of proteins known as Kaps, consisting of more than 20 members (importins, exportins, and transportins) in humans [64]. Kaps can transiently interact with Nups and their FG domains to facilitate the shuttling of specific macromolecules through the NPC [64]. Motifs adjacent to FG repeats coordinate termination of transport and release of transporting complexes from the NPC [65].

Only a few other Kaps, such as importin- $\alpha$, importin$\beta 1$, importin- $\beta 2$, and chromosome region maintenance 1 (CRM1), have been well characterized [66, 67]. The same is true for the interactions among these proteins, with only a few well elucidated, such as the link between importin $\beta 1$ and Nup153 at the nuclear face of NPCs $[44,68]$. Many transport receptors, e.g., importin- $\beta$ and NTF2, have hydrophobic binding sites on their surface for these FG-Nups [69, 70].

The NTRs bind short signaling peptides presented on their substrates for nuclear import and export. These signaling regions have been generally referred to as nuclear localization signals (NLSs) and nuclear export signals (NESs). The link established between the receptor and the shuttled substrate can be direct or mediated by additional adaptors, such as importin- $\alpha$ itself between importin- $\beta$ and cargoes [71].

The processes of shuttling cargo-receptor complexes into the nucleus or into the cytoplasm do not directly use energy from ATP/GTP hydrolysis but depend strictly on the small GTPase Ran [72-74]. The nucleoporin Nup358 (RanBP2) has four domains that can bind Ran [72]. This member of the protein Ras superfamily exists in two nucleotide states, bound to nucleotide guanine triphosphate (RanGTP) or to guanine diphosphate (RanGDP) [73, 74]. The intrinsic GTPase activity of $\operatorname{Ran}$ is low, but the GTPaseactivating protein RanGAP1 [75] catalyzes the shift between the two different forms, from cytosolic RanGTP to RanGDP [76, 77].

In contrast, the Ran guanidine exchange factor RCC1 (Regulator of chromosome condensation 1) in vertebrates can promote the exchange of guanine nucleotides by RanGDP to RanGTP in the presence of GTP [75]. This process leads to a higher nuclear concentration of RanGTP in the nucleus. A continuous supply RanGDP from the cytoplasm to the nucleus is accomplished by nuclear transport factor 2 (NTF2) [78]. RCC1 only can be found attached to nuclear chromatin to guarantee unequal distribution of GTPase Ran states, as the presence of a RanGDP/GTP gradient across the nuclear envelope gives directionality to the transport [79].

In summary, importins can recognize their cargo in the cytoplasm, where the RanGTP concentration is low, and then bind to the Nups to go through the NPC. In the nucleus, RanGTP stimulates the separation of the complex and cargo release. The importin-RanGTP complex is recycled, and the RanGTP becomes RanGDP in the cytoplasm through the activity of RanGAP. In contrast, exportins act in the nucleus only in the presence of RanGTP, forming a trimeric cargo-receptor-RanGTP complex that, once transported in the cytoplasm, undergoes dissociation (Fig. 2a-e).

NPCs are essential not only for protein shuttling across the nuclear envelope but also for RNAs that need to be exported into the cytoplasm. However, the detailed mechanism of RNA transport is not yet fully solved [80]. Several NTRs are implicated, and the directionality is 


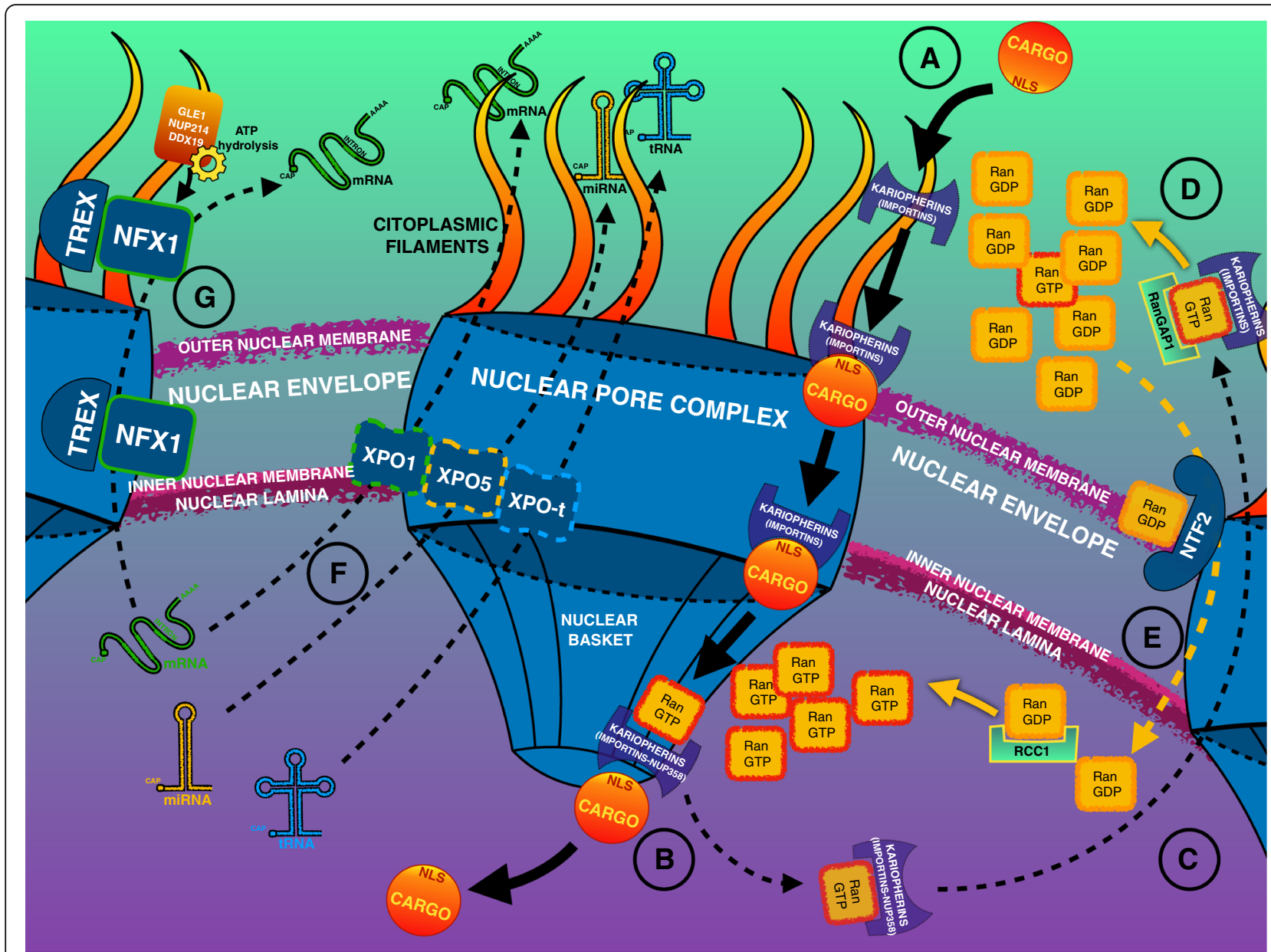

Fig. 2 Representation of the NPC structure highlighting the import-export function of proteins and transcripts. a Cargo binds importins to be shuttled to the nucleus. $\mathbf{b}$ Nuclear RanGTP induces dissociation of the importin-cargo complex. c The importins bound to RanGTP are recycled to the cytoplasm. d RanGAP1 hydrolyzes RanGTP, maintaining the RanGDP/GTP gradient across the nuclear membrane. e RanGDP is imported into the nucleus through NTF2 and converted to RanGTP by RCC1. $\mathbf{f}$ RNAs are shuttled to the cytoplasm, binding their specific exportins. $\mathbf{g}$ mRNAs only may undergo an alternative NPC transport interacting with the NFX1-TREX complex. GLE1, Nup214, and DDX19 act as NFX1 modifiers to release mRNAs into the cytoplasm

not often accomplished through the RanGDP/RanGTP gradient but by specific RNA helicases [81].

For example, exportin- $\mathrm{t}$ (XPO-t) and exportin 5 (XPO5) have key roles in shuttling specific RNAs. The former is implicated in the export of tRNAs, and the latter in the shuttling of double-stranded RNAs and premiRNAs [82, 83]. They use an RNA hairpin structure as an NES in a Ran-dependent process [84, 85]. A small subset of mRNAs use CRM1 (XPO1) for their export through the NPC [86]. The principal mRNA export receptor is NXF1 (Nuclear export factor 1) [87], which binds the mRNA in combination with several adaptors (THO complex, UAP56, and AlyRef), collectively forming the TRanscription and EXport complex (TREX) [88]. NTF2 mediates the interaction between NXF1 and the FG-Nups [89]. Once on the cytoplasmic side, Nups such as Gle1, Nup214, and the DEAD-box protein RNA helicase DDX19, that use ATP hydrolysis, revert NXF1 to a lower affinity RNA-binding state to release mRNAs [90]. The proteins involved in mRNAs shuttling are intricately linked with the mRNA modifications at several stages, including transcription, processing, splicing, and poly-adenylation (Fig. 2f-g). All these mRNA maturation processes and NCT components require a tight orchestration to ensure a correct cellular functioning.

\section{Neurodegenerative diseases}

\section{Amyotrophic lateral sclerosis and frontotemporal dementia}

ALS, also known as Lou Gehrig's disease, is a fatal neurodegenerative disease characterized by progressive loss of motor neurons in the brain and spinal cord [35]. ALS patients frequently present with behavioral and cognitive deficits, which are symptoms associated with atrophy in the frontotemporal cortex [91]. This 
particular degeneration had traditionally been linked to another disease, FTD, the most common cause of dementia after AD. Similarly, FTD patients can show motor neuron disease symptoms commonly associated with ALS [92, 93]. This duality prompted consideration of ALS and FTD as two ends of a spectrum disorder termed ALS/FTD.

Although only a small proportion of cases (10\%) with ALS/FTD are familial, genetic factors have been firmly established as causative in both familial and sporadic cases, as several mutations display a low penetrance [35]. Mutations in several genes are widely accepted as relevant in ALS, FTD, or ALS/FTD, including SOD1, TARDBP, FUS, C9ORF72, MAPT, TBK1, BCP, GLE1, OPTN, UBQLN2, SQSTM1, ANG, TUBA4A, MATR3, $V C P$, and $C H C H D 10$ [35].

ALS and FTD cases with different monogenic forms present distinctive molecular neuropathologic signatures. The findings range from inclusions of TDP-43 to FUS and TAU to no inclusions of these proteins, as observed in patients with SOD1 mutations [94]. In post-mortem brains of most patients with sporadic ALS/FTD (97\% of ALS and $50 \%$ of FTD) [95], TDP-43 and FUS show an altered subcellular localization and appear to be at least partially lost from the nucleus in neuronal and glial cells [94].

Moreover, substantial evidence implicates oxidative stress as a central mechanism of motor neuron death in ALS [96].

TDP-43-related pathology TARDBP encodes the predominantly nuclear RNA-binding TDP-43, a protein with a NLS and a "putative" NES that can shuttle between the nucleus and cytosol [97]. In addition to nuclear functions, TDP-43 is involved in multiple processes in the cytoplasm, including mRNA stability, transport, and translation [98]. TDP-43 is essential for neuronal survival and selective neuronal degeneration appears in the presence of pathological TDP-43 [99, 100]. The precise mechanism by which TDP-43 passes through the nuclear membrane is unclear; however, recent evidence suggests that despite the predicted NES, the protein is exported independently of the export receptor CRM1/XPO1 [101-103]. Thus, no single exporter is necessary for TDP-43 export and TDP-43 nuclear egress seems to follow a model of passive diffusion; these findings, provided by silencing specific Nups in Hela cells, suggest that redundant pathways regulate its transport $[101,102]$. Other factors may influence TDP-43 cytoplasmic translocation, as recently demonstrated for the tumor-suppressor folliculin protein, which directly interacts with the RNA-recognition motif domain [104]. These experiments, performed in non-neuronal cell lines and in rat primary cortical neurons, leave unexplored the possibility of other mechanisms specific of human neurons, this should be investigated in future experiments [102].

Whether the TDP43 pathology causes import-export defects or whether defects in NPC components precede the TDP43 pathology is still unclear. TDP-43 is imported into the nucleus by the import pathway Kaps $\alpha / \beta 1$, using the Ran GDP/GTP gradient; "Kap $\alpha$ " is recycled to the cytoplasm via cellular apoptosis susceptibility protein (CAS) [105]. Disruption of this pathway in human and mouse neuroblastoma cell lines and primary murine cortical neurons, by downregulation of Kap $\beta 1$ or CAS, leads to TDP-43 cytoplasmic accumulation [105]. Of note, some studies have shown decreased levels of CAS, Kap $\alpha 2$, or $\alpha 6$ in motor neurons of FTD patients with TDP-43 mutations and in ALS patients [105]. Direct evidence of TDP-43 translocation to the cytoplasm was nicely demonstrated in vivo in zebrafish, with an innovative fluorescent tool that visualizes the dynamic of protein transport in neurons [106]. In particular, TDP43 reaches the cytoplasm, dendrites, and extracellular matrix, inducing neuronal cell death, and can form cytoplasmic aggregates in the absence of microglia [106].

However, if TDP-43 translocation after UV-mediated injury affects also other neuronal subtypes is still unexplored. Future studies aimed at filling this gap might help to clarify the mechanisms of motor neuron pathology selectivity in ALS/FTD.

TDP-43 pathology causes the mislocalization and aggregation of Nups and transport factors, as well as disruption of nuclear membrane and NPCs, leading to impaired nuclear protein import and mRNA export [34]. Differently, nuclear alterations of Nup62 or Kap $\beta 1$ have been detected by nuclear staining of spinal motor neurons from ALS patients [107]. Recently, new emerging observations show that ribonucleoprotein complexes, such as those containing TDP-43, form liquid droplets with different biophysical characteristics at different neuronal sub-cellular locations [36, 108]. Interestingly, mutations of TDP-34 may confer toxic properties to these droplets [108]. Furthermore, TDP-43 was shown to undergo phase-separation into liquid droplets in the cytosol in vivo after TDP-43 overexpression or exposure to amyloid-like fibrillar TDP-43 or FUS [36]. Droplets of cytosolic TDP-43 were shown to recruit importin- $\alpha$ and Nup62, and to induce mislocalization of RanGap1, Ran, and Nup107, with the consequent inhibition of NCT [36]. Further experiments in this promising direction will define the intricate interplay between the role of pathological aggregates and the alteration of Nups and consequently of the NCT, perhaps also taking into consideration other neurodegenerative pathologies characterized by alterations of different ribonucleoproteins.

Experimental models using Neuroblastoma cell lines overexpressing several Nups and wild-type or mutated 
TDP-43 have shown that FG repeat-containing Nups, scaffold Nups, and nuclear export factors co-aggregate with mutated TDP-43. Nup205 has been found to mislocalize in patients' fibroblasts, induced pluripotent stem cell (iPSC)-derived motor neurons, and showed coaggregation with TDP-43 positive cytoplasmic inclusions in brain tissue of ALS patient [34]. Starting from these observations, future studies evaluating additional Nups mislocalization and co-aggregation with TDP-43 in ALS and FTD brain samples and iPSCs-derived motor neurons will define a clearer picture of the neurodegenerative process involving NPC and protein aggregates. In the same study, NPC defects in the Drosophila model expressing human mutant TDP-43 could be rescued by reducing TDP-43 aggregates and vice versa, suggesting a complex interplay of both components of the degenerative process [34]. In ALS/FTD fly models with the hexanucleotide C9ORF72 repeat expansion, accumulated cytosolic TDP-43 is found to cause Kap $\alpha 2 / \alpha 4$ pathology, to increase levels of dipeptide repeat proteins (DPRs), and to enhance expansion-related toxicity [109].

Finally, actin polymerization was recently linked to NPC integrity and function. Modulation of actin homeostasis in primary motor neurons seems to rescue NPC instability arising from mutant Profilin1 and C9ORF72 repeat expansion [110].

FUS-related pathology The term "FUSopathies" designates neurodegenerative diseases characterized by neuronal and glial cytoplasmic fused in sarcoma (FUS) inclusions [111]. Cytoplasmic aggregates of FUS can be found in $5 \%$ of familial ALS and up to $10 \%$ of ALS/FTD brains. Mutations in the FUS gene occur in 5\% of familial ALS and $<1 \%$ of sporadic ALS cases, but are rare in FTD [112-114].

FUS is a predominantly nuclear protein with DNA and RNA binding properties involved in regulating transcription, splicing, miRNA biogenesis, and RNA transport $[115,116]$. Among its functions, FUS is also essential for DNA repair, being recruited by PARP1 at DNA damage sites $[117,118]$. It belongs to the family of RNA-binding proteins known as FET (FUS/ TLS, EWS, and TAF15). At their C-terminus, FET proteins have a homologous PY-NLS motif interacting with $\beta$-Kaps TNPO1 or TNPO2, which are involved in nuclear import $[119,120]$. FUS was seen to translocate through a calcium-dependent mechanism, and NCT alterations result from its cytosolic translocation [121]. The majority of ALS-associated FUS mutations affect the C-terminal NLS, interfering with TNPO1 binding and consequently leading to FUS cytoplasmic accumulation [122]. Post-translational modifications of FET proteins can trigger the same outcome, affecting their interaction with TNPO1 [123].
FUS inclusions in ALS and FTD differ in that FUS is methylated in ALS and not methylated in FTD. In the first case, TNPO1 does not co-localize with the inclusions, and FUS is not properly imported into the nucleus. In the second, FUS inclusions are not methylated, and TNPO1 co-localizes with FUS inclusions, implicating other factors in cytoplasmic accumulation of the protein [123, 124].

Several lines of evidence suggest a major role of DNA repair impairment resulting from FUS mutations $[125,126]$. Loss of nuclear FUS causes DNA nick ligation defects in motor neurons because of reduced recruitment of XRCC1/LigIII to DNA strand breaks, a mechanism that also has recently been associated with AOA4 $[125,126]$.

In iPSC-derived motor neurons, the induced DNA damage leads to FUS mislocalization in the cytosol, enhancing a vicious cycle by increasing cytoplasmic FUS shuttling [127]. The trigger of FUS cytoplasmic accumulation by XPO1 is a still controversial issue. So far, the most important link between NPC and neurodegeneration associated with FUS pathology derives from a study using transgenic flies. In this model, cytoplasmic stress granules containing FUS could be rescued by downregulating XPO1 or Nup154 (Nup155 in humans), proteins needed to export FUS from the nucleus [101, 128]. To clarify the role of NPC in FUS related-ALS and FTD, further studies aimed at exploring the NPC defects and FUS transport in brain tissues and iPSC-derived neurons are needed.

C9ORF72-related pathology GGGGCC repeat expansion in the noncoding region of C9ORF72 accounts for up to $80 \%$ of familial ALS/FTD, $20-50 \%$ of familial ALS, $5-20 \%$ of sporadic ALS, and $10-30 \%$ of FTD cases [129-131]. Of note, most patients with ALS carrying the expansions present TDP-43 pathology [95]. How C9ORF72 dysfunction leads to neurodegeneration is a matter of intensive debate. Some lines of evidence suggest a reduction in C9ORF72 transcript expression in cell lines carrying the pathological expansion, which lies in the promoter region [132]. However, C9ORF72 knockout mice do not show neurodegeneration, raising concerns about haploinsufficiency as a primary cause of the disease [133-136]. In this view, the observation that patients who are homozygous for C9ORF72 expansion have similar phenotypes to those who are heterozygous suggests a less important role of haploinsufficiency.

Cytoplasmic and nuclear RNA foci formed by the expanded GGGGCC repeat transcripts have been suggested to sequester RNA binding proteins and alter RNA metabolism as possible mechanisms underlying the disease [137]. The expanded hexanucleotide repeat 
disrupts nucleolar integrity by binding the aborted transcripts to nucleolin [138]. Of interest, nucleolar disruption also has been observed in BAC transgenic mice, Drosophila, human motor neurons derived from patient iPSCs, and brains [131, 139].

C9ORF72 is also translated by an alternative mechanism to produce sense and antisense transcripts, which undergo repeat-associated non-AUG translation in all reading frames [140]. Repeat-associated nonAUG encodes five species of highly toxic DPRs, glycine-proline (GP), glycine-alanine (GA), glycinearginine $(\mathrm{GR})$, proline-alanine (PA), and prolinearginine (PR) $[141,142]$. RNA foci and DPR proteins are found in the brains of C9ORF72-ALS/FTD patients, in human motor neurons derived from C9ORF72-iPSCs [143-145], and in C9ORF72 BAC transgenic mice [139, 146, 147]. In Drosophila, GR and PR DPRs show toxicity, while RNA-only repeat PA or GA DPRs are not sufficient to induce degeneration [148]. In line with these findings, studies on yeast and flies confirm the toxicity of argininecontaining DPR proteins and the modifying effect of components of the NCT $[149,150]$. DPRs also interact with many proteins components of the NCT [149-152]. Most proteins that interact with DPRs are low complexity domain proteins, including FUS and TDP-43 [152]. Moreover, a large-scale genetic screen approach in Drosophila showed an enhancement or suppression of the expansion toxicity related to several Nups, including Nup50, Nup152, TNPO1, protein shuttle mediators like Nup50, Ran, CRM1, and KPNB1, and RNA-exportins (TREX complex NXF1, Nup107, Nup160, EXOSC3, GLE1, CRM1, and others) [153]. Worth special mention are EXOSC3 and GLE1, which are strong enhancers of C9ORF72 expansion toxicity and causative in a rare form of motor neuron disease [141].

In line with the critical role of NCT-associated proteins in C9ORF72 pathology is the finding of reduced toxicity linked to the expansion if RanGAP is overexpressed in Drosophila [154]. Nuclear retention of RNAs has been observed in C9ORF72 iPSC-derived cortical neurons, indicating impairment of nuclear RNA export. Moreover, C9ORF72 iPSC-derived neurons display a reduced nucleo-cytoplasmic ratio of Ran and RCC1, leading to defects in the NCT mechanism [150]. Recently, the mislocalization of the RNA-editing enzyme adenosine deaminase, which acts on RNA 2 (ADAR2), was found in C9ORF72associated ALS/FTD, and is possibly responsible for the associated alterations in RNA processing events [155].

Taken together, these studies suggest that C9ORF72 expansion may play distinctive roles in inducing neurodegeneration, and DPRs that lead to NCT defects is a primary pathogenic mechanism.
SOD1-related pathology SOD1 mutations are present in approximately $15 \%$ of familial and $1-3 \%$ of sporadic ALS cases [156]. Although SOD1 was the first gene causatively linked to ALS, no widely accepted mechanisms have emerged to explain the toxicity of the mutant protein [35]. Several hypotheses have been proposed, from the impaired superoxide dismutase activity to misfolded protein aggregation and microglia activation [35]. The loss of the antioxidant function of $\mathrm{Cu}$, $\mathrm{Zn}$-superoxide dismutase leads to RNA oxidation and selective motor neuron degeneration [156, 157].

Some recent evidence suggests an impact of SOD1 mutations on NCT. Mice expressing mutant SOD1 show misregulation of different NPC components and import factors [158]. Specifically, a transgenic G93A mouse displays reduced immunoreactivity of importin- $\alpha$ and importin- $\beta$ in the nucleus, with an increase in the cytoplasm [158]. In the same mouse model, the nuclear membrane shows irregular Nup62 staining, and Lewy body-like hyaline cytoplasmic inclusions are found in spinal motor neurons $[158,159]$. Finally, irregular NM morphology was found in spinal motor neurons of ALS patients with SOD1 mutations. Taking as examples the murine models, studies aimed at investigating alterations of several Nups in cortical and spinal motor neurons of patients with SOD1 mutations will be useful to understand whether a more complex defect of NPCs and NCT underlines the observed nuclear membrane alterations [159].

GLE1-related pathology GLE1 was first identified as causative in a severe autosomal recessive lethal congenital contracture syndrome 1 and lethal arthrogryposis with anterior horn cell disease [160, 161]. Later, nonsense and missense mutations in this gene were found in ALS [162].

GLE1 is a conserved multifunctional protein that regulates gene expression, and its role has been studied in several processes, including nuclear mRNA export, translation initiation, and termination [163]. GLE1 interacts with the nucleoporin Nup155 [161], and impairment in GLE1 thus is expected to lead to NCT deficiencies. GLE1 mutations found in ALS are linked to mRNA degradation and reduced interaction with NupL2 [162]. Moreover, GLE1 is a strong enhancer of C9ORF72 expansion-related toxicity in a Drosophila model [141].

\section{Huntington's disease}

A consistent proportion of NCT impairment in neurodegenerative diseases is represented by the polyglutamine expansion that interferes with the normal structure and function of the NPC [164]. In HD, the CAG repeat expansion in the Huntingtin (HTT) gene is responsible for most of the deleterious effects that lead to death of striatum medium spiny neurons $[165,166]$. Among these 
mechanisms, damage of polyglutamine on the neurons can be mediated by interference with NCT components, or a direct impairment of NPCs, or indirect interaction with specific Nups. An example of the former is the interaction between the N-terminal of HTT and XPO1, shown in HEK cells, which promotes shuttling between the cytoplasm and nucleus [167]. These fragments also interact with Nup TPR to export HTT from the nucleus, a mechanism that is impaired in the presence of pathological polyglutamine expansion [38]. Studies about HTT-NCT performed on iPSC-derived neurons would help to better comprehend these mechanisms and the selectivity of the disease to specific neuronal populations.

The finding of GLE1 among proteins sequestered within polyglutamine inclusions in HD suggests an indirect mechanism of HTT interference with NPCs and further establishes a link between HTT expansion and NPC defects [168]. Moreover, oxidative stress has long been held to be key to disease progression in HD [169]. Several other recent lines of evidence suggest a role for HTT and its interactions with NCP in neurodegeneration [37]. In mouse models of $\mathrm{HD}$, for example, several proteins important for NCT, including RanGAP1, Nup62, and Nup88, form intranuclear inclusions that co-localize with HTT aggregates in striatal and cortical neurons [37].

A Drosophila model highlights the importance of antisense repeat-associated non-ATG (RAN) proteins in nuclear import [170]. These proteins accumulate in several brain regions with neuronal loss and microglia, including the striatum and white matter [170]. Of note, the pathological phenotype in Drosophila is enhanced with the expression of a dominant-negative form of Ran and rescued by the overexpression of Ran and RanGAP1, which seem to be neuroprotective in HD [37]. In HD patients' iPSC-derived neurons, the MAP2 nucleo-cytoplasm ratio is significantly increased, indicating that NPCs may be damaged and dysfunctional [37]. Additional results along these lines come from neuropathological analyses of brains from patients with HD. Staining for RanGAP1 and Nup62 showed profound mislocalization in striatal neurons, consistent with the observation of selective striatal pathology in infantile bilateral striatal necrosis caused by Nup62 mutations [37].

\section{Other neurodegenerative disorders with expansion repeats}

Spinocerebellar ataxias include several autosomal dominant forms and one recessive form, which are caused by the expansion of CAG or CGG repeats. In spinocerebellar ataxia (SCA) 1-2-3-6-7-17 and Friedreich's ataxia, the CAG expansions encode for polyglutamine [171]. Other forms (SCA 8-10-31-36) are not polyglutamine repeat diseases, however, and the expansions may follow an aberrant pathogenic mechanism similar to that of C9ORF72. In particular, various combinations of the expansions (GGGGCC-sense and GGCCCC-antisense) are improperly translated into RAN proteins, which are known to be toxic for the cell [164].

For example, Ataxin-3 enters into the nucleus through NPCs, imported by importin $\alpha / \beta$. XPO1 and Kap $\alpha 3$ modulate trafficking in HEK cells, Drosophila, and mice. Increased cytoplasmic localization of the expanded Ataxin-3 and reduction of protein aggregates have been observed by Kap $\alpha 3$ knockdown and XPO1 overexpression $[172,173]$. The altered interaction between Kap $\alpha 3$ and pathologic expanded Ataxin-3 may suggest a link between the pathogenic mechanism and the NCT, but further studies are needed.

Myotonic dystrophy type 1 (DM1) is caused by CGG repeat expansion in the $3^{\prime}$ untranslated region, similar to the site of expansion in SCA8. Reduced levels of Ref1, the Drosophila orthologue of AlyRef in mammals, exacerbates neurodegeneration in a DM1 model of Drosophila, suggesting a possible underlying role of an impaired RNA transport mechanism, which deserves more studies [164].

RAN proteins translation also appears to have a prominent role in the nuclear retention of transcripts in Fragile- $X$ tremor ataxia syndrome [174]. Fragile-X tremor ataxia is caused by the premutation of FMR1 CGG promoter expansion [175, 176], possibly indicating a pathogenic mechanism similar to that observed in HD, which is an interesting avenue of study to pursue. The protein encoded seems to be important during neural differentiation to read N6-methyladenosine modification of mRNA and promote nuclear export of methylated mRNAs [177].

Recently, impairment in the nuclear export of polyQexpanded androgen receptor and formation of intranuclear inclusions were demonstrated in spinal and bulbar muscular atrophy [178]. In dentatorubral-pallidoluysian atrophy, which is dominantly caused by a CAG repeat in the Atrophin1 gene, neuropathological findings show intranuclear filamentous inclusions and nuclear membrane defects in cerebellar granule cells, suggesting defects in NCT function or in NPC machinery $[179,180]$.

\section{Recessive ataxia syndromes}

SETX encodes the RNA/DNA helicase Senataxin. Mutations in this gene are responsible for ataxia with oculomotor apraxia (AOA) type 2 and have been linked to NCT impairment [173, 181].

In transgenic mice harboring a single SETX human mutation, the nuclear membrane appears damaged. The protein is less able to reach the nucleus in the presence of mutations, leading to DNA/RNA defects. In SETX knock-in mice, motor neurons and primary neuronal 
cultures show mislocalization of TDP-43 and FUS in the cytoplasm [173]. SETX mutations also have been reported in rare juvenile forms of ALS [182], prompting speculation about a possible link between motor neuron degeneration and TDP-43/FUS alterations.

Aprataxin, a protein involved in single-strand DNA repair breaks, is mutated in AOA type 1 [183]. Aprataxin reaches the nucleus to exert its function, binding NPCs [184]. In particular, it interacts with Kap $\alpha / \beta$ and binds the nucleoporin Aladin on the cytoplasmic side of the NPC, initial steps for import into the nucleus. This pattern suggests the importance of a correct NCT for Aprataxin to reach the nucleus and guarantees optimal DNA maintenance, which is particularly relevant for nondividing cells.

Recently, mutations in the Nup93 were identified in an autosomal form of congenital ataxia [185]. In all of these rare forms of neurodegenerative syndromes, NPC and NCT appear to be relevant, but these preliminary observations need to be further studied.

\section{Parkinson's disease}

Cytoplasmic accumulation of the protein alphasynuclein in dopaminergic neurons of the substantia nigra is the hallmark of PD [186]. Alpha-synuclein belongs to the family of synucleins, which are proteins identified inside the nucleus, although their normal localization is in the cytoplasm. Different alphasynuclein species bind the chromatin to induce a transcriptional modification [187]. In this role, alphasynuclein needs phosphorylation at S129, which is specifically found in neurons of patients with an aggressive form of parkinsonism, called Lewy body dementia. Whether alpha-synuclein is transported into the nucleus is still unknown, and uncovering a possible pathological effect of alpha-synuclein aggregates on NPCs or NCT may shed light on the mechanism of PD-related neurodegeneration [187]. Oxidative damage contributes to the cascade of events leading to degeneration of highly functioning dopaminergic neurons in PD [188].

Further suggesting a possible link between altered NCT and PD, several studies have demonstrated a mislocalization of specific transcription factors in PD brains. In particular, NF- $\mathrm{KB}$ shows increased nuclear translocation in dopaminergic neurons of PD [189]. In addition, cytoplasmic aggregates of pCREB and the lack of the expected nuclear staining are observed in PD substantia nigra pars compacta [190]. In line with this observation, primary midbrain cultures treated with 6hydroxydopamine show progressive accumulation of PCREB in the cytoplasm and decreased pCREB in the nucleus of dopaminergic neurons but not in nondopaminergic neurons [190].
Of note, proteins involved in recessive forms of $\mathrm{PD}$ have also been found to interact with Nups. Parkin, encoded by PARK2, is mutated in juvenile PD. It is an E3 ubiquitin ligase and specifically ubiquitinates Nup358/RanBP2, a protein fundamental to binding Ran to NPCs [191]. The role of alpha-synuclein in PARK2-related PD is controversial because most studies do not show alpha-synuclein accumulation in dopaminergic neurons in patients with Parkin mutations [192-194]. In addition, mice lacking one copy of Nup358/RanBP2 and treated with 1-methyl-4-phenyl-1,2,3,6-tetrahydropyridine, known to induce a PD-phenotype in animal models, have a more severe disease course and slower recovery $[195,196]$. These findings suggest that NPC alterations in PD might occur regardless of alphasynuclein accumulation. Further studies are needed to corroborate these initial observations of NCT impairment in PD, with a focus on the role of alpha-synuclein or other possible mechanisms.

\section{Alzheimer's disease}

The classical pathological hallmarks of AD consist of deposition of beta-amyloid in cortical plaques, hyperphosphorylation of tau, and formation of neurofibrillary tangles, causing neuronal degeneration [197]. Initial observations suggest the presence of nuclear membrane alteration and aggregation of NPC in AD brains [198, 199]. Of interest, NTF2 accumulates in the cytoplasm of some hippocampal $\mathrm{AD}$ neurons regardless of the presence of tangles, and accumulation of importin- $\alpha 1$ has been found in CA1-hippocampal neuronal inclusions in AD brains [200]. More recently, the number of NPCs has been found to be significantly reduced in AD brains [40], and Ran-reduced expression has also been reported in postmortem tissues from AD cases [201].

The precise mechanism that leads to protein mislocalization is not clear, but one significant finding has demonstrated a link between aberrant tau accumulation and NPC impairment in AD [40]. In particular, that study provided evidence that ADrelated tau disrupts nuclear pore function in $\mathrm{AD}$ and that Nups can trigger tau to aggregate. Specifically, one component of the NPC, Nup98, interacts with tau, facilitating its aggregation. In addition, in AD brains and tau-mutated mouse models, Nup98 is mislocalized into the cytoplasm [40]. This Nup98 mislocalization and NCT impairment can be rescued by solubilizing tau aggregates in mice. Hyperphosphorylated and mislocalized tau protein has been found also in FTD-MAPT neurons to lead to microtubules impairment and to damage the nuclear membrane [202, 203].

Finally, the Musashi (MSI) family of RNA-binding proteins has been recently investigated using a tau-inducible 
HEK model. Tau co-localizes with MSI proteins in the cytoplasm and nucleus, altering the nuclear transport of MSI and inducing structural changes to LaminB1, leading to nuclear instability [204].

\section{Allgrove syndrome}

A dysfunctional NCT system has been proposed to operate in triple-A syndrome, also known as Allgrove syndrome [11, 184, 205]. This rare disorder is caused by mutations in a gene that encodes the Nup Aladin. Affected fibroblasts exhibit an impaired importin- $\alpha$-mediated import pathway and weak nuclear import of Aprataxin and DNA ligase I $[159,206]$. As a result, cells become more susceptible to oxidative stress, accumulate damaged DNA, and undergo cell death [159]. Of interest, patients with Allgrove syndrome display a peculiar brain multisystem neurodegenerative involvement, affecting motor neurons, Purkinje cells, striatal neurons, autonomic system, peripheral nerves, and endocrine system at the same time [207]. This disease could serve as an example model to study how the same mechanism (an NPC impairment) could underlie neurodegeneration of different neuronal systems.

\section{Aging}

In cells with a peculiar characteristic of being long-lived and non-dividing, the integrity of the genome is a fundamental issue [208]. Neurons are such cells: they do not rely on mitosis to renew their DNA and are strictly dependent for their entire lifespan on the mechanisms that guarantee the protection of DNA from external (toxins) and internal (ROS) damage. In this attempt, the machinery that provides a proper nuclear supply of DNA repair proteins (i.e., Aprataxin) and ROS scavengers must work efficiently [209]. The progressively reduced efficiency of this process and the accumulation of ROS and DNA damage lead to physiological cellular aging [210, 211].

Because the NCT is responsible for the supply role, an impaired NPC function may accelerate the alterations observed in the aging process. An example of accelerated aging from NCT deficiency is Hutchinson-Gilford progeria syndrome. This inherited laminopathy causes premature, rapid aging shortly after birth. In this syndrome, a mutant form of Lamin A leads to a dysmorphic nuclear lamina structure with the consequent alteration of the physiological RanGDP/GTP gradient, essential for a proper NCT functionality [212, 213].

Several pieces of evidence link neuronal aging with progressive NPC leaking. Aging-related progressive reduced density of NPCs has been found in the dentate gyrus of hippocampal rat neurons [214] Other studies have demonstrated altered Nups composition and turnover in aged rat neurons $[215,216]$. Moreover, in iPSC-derived neurons and directly reprogrammed induced neurons from young and old humans, RanBP17 is reduced in older cells [217]. The reduced levels of this nuclear import receptor have a direct impact on the ability of aged neurons to maintain proper nuclear compartmentalization [217]. For these reasons, more elucidation of the function of Nups and their relationship with aging will significantly affect our understanding of the association of neuronal frailty with aging, opening the way to targeting the underlying molecular mechanisms.

\section{Conclusions}

The evidence clearly indicates that NCT rely on NPCs as key factors in neuronal health and vitality. Many alterations lead to a broad spectrum of neurodegenerative patterns and to neuronal aging. The most important aspects seem to involve the maintenance of a proper RanGDP/GTP gradient and the shuttling of transcription factors and proteins involved in protein and RNA conservation. However, most of the studies investigating these mechanisms are focused on ALS and FTD models, and a deep investigation of the link of NCT, NPC and neuronal cell death is needed in other neurodegenerative diseases, especially the most common $\mathrm{AD}$ and $\mathrm{PD}$. Moreover, to confirm the observations from animal experimental models, additional studies on human iPSCderived neurons and neuropathological samples are needed. The reason specific neuronal subsets are variably susceptible to specific damage that leads to different phenotypes of neurodegenerative diseases remains unclear. The study of emblematic but rare diseases that display an NPC-related impairment in different neuronal types, such as Allgrove syndrome, may shed light on common mechanisms underlying these neurodegenerative processes. Moreover, targeting NCT deficiency as a common pathway of several neurodegenerative diseases and neuronal aging may represent a unique therapeutic opportunity for these incurable disorders.

\footnotetext{
Abbreviations

AD: Alzheimer's disease; ADAR2: Enzyme adenosine deaminase acting on RNA 2; ALS: Amyotrophic lateral sclerosis; AOA: Ataxia with oculomotor apraxia; CAS: Cellular apoptosis susceptibility protein; CRM1: Chromosome region maintenance 1; DM1: Myotonic dystrophy type 1; DPR: Dipeptide repeat proteins; FG: Phenylalanine-glycine; FTD: Frontotemporal dementia; GA: Glycine-alanine; GP: Glycine-proline; GR: Glycine-arginine;

HD: Huntington's disease; HTT: Huntingtin; Kaps: Karyopherins; MSI: Musashi; NCT: Nucleo-cytoplasmic transport; NES: Nuclear export signal; NLS: Nuclear localization signal; NPC: Nuclear pore complex; NTF2: Nuclear transport factor 2; NTRs: Nuclear transport receptors; Nups: Nucleoporins; NXF1: Nuclear export factor 1; PA: Proline-alanine; PD: Parkinson's disease; PR: Prolinearginine; RAN: repeat-associated non-ATG; Ran: Ras-related nuclear protein; RCC1: Regulator of chromosome condensation 1; ROS: Radical oxygen species; SCA: Spinocerebellar ataxia; TREX: Transcription and export complex; XPO-t: Exportin-t; XPO5: Exportin-5
}

Acknowledgements

The authors would like to acknowledge the Fresco Institute for support. 


\section{Authors' contributions}

GB, ADF: reviewing the literature, writing the manuscript. The author(s) read and approved the final manuscript.

\section{Funding}

None.

\section{Availability of data and materials}

Not applicable.

\section{Ethics approval and consent to participate}

Not applicable.

\section{Consent for publication}

Not applicable.

\section{Competing interests}

The authors declare that they have no competing interests.

Received: 11 December 2019 Accepted: 1 June 2020

Published online: 03 July 2020

\section{References}

1. Taylor JP, Hardy J, Fischbeck KH. Toxic proteins in neurodegenerative disease. Science. 2002;296:1991-5.

2. Nouspikel T, Hanawalt PC. When parsimony backfires: neglecting DNA repair may doom neurons in Alzheimer's disease. BioEssays News Rev Mol Cell Dev Biol. 2003:25:168-73.

3. Bender A, Krishnan KJ, Morris CM, Taylor GA, Reeve AK, Perry RH, et al. High levels of mitochondrial DNA deletions in substantia nigra neurons in aging and Parkinson disease. Nat Genet. 2006;38:515-7.

4. Katyal S, McKinnon PJ. DNA strand breaks, neurodegeneration and aging in the brain. Mech Ageing Dev. 2008;129:483-91.

5. Wente SR, Rout MP. The nuclear pore complex and nuclear transport. Cold Spring Harb Perspect Biol. 2010;2:a000562.

6. Strambio-De-Castillia C, Niepel M, Rout MP. The nuclear pore complex: bridging nuclear transport and gene regulation. Nat Rev Mol Cell Biol. 2010; 11:490-501.

7. Kulkarni A, Wilson DM. The involvement of DNA-damage and -repair defects in neurological dysfunction. Am J Hum Genet. 2008;82:539-66.

8. Hoeijmakers JHJ. DNA damage, aging, and cancer. N Engl J Med. 2009;361: 1475-85.

9. Boehringer A, Bowser R. RNA nucleocytoplasmic transport defects in neurodegenerative diseases. In: Sattler R, Donnelly CJ, editors. RNA Metab Neurodegener Dis. Cham: Springer International Publishing; 2018. p. 85-101. Available from: http://link.springer.com/10.1007/978-3-319-89689-2_4. [cited 2018 Sep 16].

10. Ori A, Banterle N, Iskar M, Andrés-Pons A, Escher C, Khanh Bui H, et al. Cell type-specific nuclear pores: a case in point for context-dependent stoichiometry of molecular machines. Mol Syst Biol. 2013;9:648.

11. Cronshaw JM, Matunis MJ. The nuclear pore complex protein ALADIN is mislocalized in triple A syndrome. Proc Natl Acad Sci. 2003;100:5823-7.

12. Cronshaw JM, Krutchinsky AN, Zhang W, Chait BT, Matunis MJ. Proteomic analysis of the mammalian nuclear pore complex. J Cell Biol. 2002;158:915-27.

13. Wozniak R, Burke B, Doye V. Nuclear transport and the mitotic apparatus: an evolving relationship. Cell Mol Life Sci CMLS. 2010;67:2215-30.

14. Weis K. Regulating access to the genome: nucleocytoplasmic transport throughout the cell cycle. Cell. 2003;112:441-51.

15. Cronshaw JM, Matunis MJ. The nuclear pore complex: disease associations and functional correlations. Trends Endocrinol Metab. 2004;15:34-9.

16. Izaurralde E, Mattaj IW. RNA export. Cell. 1995:81:153-9.

17. Moore MS, Blobel G. A G protein involved in nucleocytoplasmic transport: the role of Ran. Trends Biochem Sci. 1994;19:211-6.

18. Koonin EV, Aravind L. Comparative genomics, evolution and origins of the nuclear envelope and nuclear pore complex. Cell Cycle Georget Tex. 2009:8:1984-5.

19. Bapteste E, Charlebois RL, MacLeod D, Brochier C. The two tempos of nuclear pore complex evolution: highly adapting proteins in an ancient frozen structure. Genome Biol. 2005;6:R85.
20. Pan L, Penney J, Tsai L-H. Chromatin regulation of DNA damage repair and genome integrity in the central nervous system. J Mol Biol. 2014; 426:3376-88

21. $R M, L P, L h T$. DNA damage and its links to neurodegeneration. Neuron. 2014; [cited 2020 May 23]. Available from: https://pubmed.ncbi.nlm.nih. gov/25033177/.

22. Finkel T, Holbrook NJ. Oxidants, oxidative stress and the biology of ageing Nature. 2000:408:239-47.

23. Mattson MP, Magnus T. Ageing and neuronal vulnerability. Nat Rev Neurosci. 2006;7:278-94.

24. Lodato MA, Rodin RE, Bohrson CL, Coulter ME, Barton AR, Kwon M, et al. Aging and neurodegeneration are associated with increased mutations in single human neurons. Science. 2018;359:555-9.

25. Pj M. DNA repair deficiency and neurological disease. Nat Rev Neurosci. 2009; Available from: https://pubmed.ncbi.nlm.nih.gov/19145234/. [cited 2020 May 23]

26. Kim HJ, Taylor JP. Lost in transportation: nucleocytoplasmic transport defects in ALS and other neurodegenerative diseases. Neuron. 2017;96:285-97.

27. Patel VP, Chu CT. Nuclear transport, oxidative stress, and neurodegeneration. Int J Clin Exp Pathol. 2011;4:215-29.

28. Robijns J, Houthaeve G, Braeckmans K, De Vos WH. Loss of nuclear envelope integrity in aging and disease. Int Rev Cell Mol Biol. 2018:205-22 Available from: https://linkinghub.elsevier.com/retrieve/pii/S19376448173 00886. [cited 2018 Sep 16]

29. Xie Y, Ren Y. Mechanisms of nuclear mRNA export: a structural perspective. Traffic Cph Den. 2019;20:829-40.

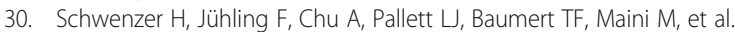
Oxidative stress triggers selective tRNA retrograde transport in human cells during the integrated stress response. Cell Rep. 2019;26:3416-3428.e5.

31. Sotelo C, Dusart I. Intrinsic versus extrinsic determinants during the development of Purkinje cell dendrites. Neuroscience. 2009;162:589-600.

32. Madabhushi R, Kim T-K. Emerging themes in neuronal activity-dependent gene expression. Mol Cell Neurosci. 2018;87:27-34

33. Van Driesche SJ, Martin KC. New frontiers in RNA transport and local translation in neurons. Dev Neurobiol. 2018;78:331-9.

34. Chou C-C, Zhang Y, Umoh ME, Vaughan SW, Lorenzini I, Liu F, et al. TDP-43 pathology disrupts nuclear pore complexes and nucleocytoplasmic transport in ALS/FTD. Nat Neurosci. 2018;21:228-39.

35. Taylor JP, Brown RH, Cleveland DW. Decoding ALS: from genes to mechanism. Nature. 2016:539:197-206.

36. Gasset-Rosa F, Lu S, Yu H, Chen C, Melamed Z, Guo L, et al. Cytoplasmic TDP-43 de-mixing independent of stress granules drives inhibition of nuclear import, loss of nuclear TDP-43, and cell death. Neuron. 2019;102: 339-357.e7

37. Grima JC, Daigle JG, Arbez N, Cunningham KC, Zhang K, Ochaba J, et al. Mutant huntingtin disrupts the nuclear pore complex. Neuron. 2017:94:93-107.e6.

38. Cornett J, Cao F, Wang C-E, Ross CA, Bates GP, Li S-H, et al. Polyglutamine expansion of huntingtin impairs its nuclear export. Nat Genet. 2005;37:198-204

39. Li N, Lagier-Tourenne C. Nuclear pores: the gate to neurodegeneration. Nat Neurosci. 2018;21:156-8.

40. Eftekharzadeh B, Daigle JG, Kapinos LE, Coyne A, Schiantarelli J, Carlomagno $Y$, et al. Tau protein disrupts nucleocytoplasmic transport in Alzheimer's disease. Neuron. 2018:99:925-940.e7.

41. Sakuma S, D'Angelo MA. The roles of the nuclear pore complex in cellular dysfunction, aging and disease. Semin Cell Dev Biol. 2017;68:72-84.

42. Ciechanover A, Kwon YT. Degradation of misfolded proteins in neurodegenerative diseases: therapeutic targets and strategies. Exp Mol Med. 2015:47:e147.

43. De Magistris $P$, Antonin W. The dynamic nature of the nuclear envelope Curr Biol. 2018:28:R487-97.

44. de las Heras Jl, Meinke P, Batrakou DG, Srsen V, Zuleger N, Kerr AR, et al. Tissue specificity in the nuclear envelope supports its functional complexity. Nucleus. 2013;4:460-77.

45. Amendola M, van Steensel B. Mechanisms and dynamics of nuclear laminagenome interactions. Curr Opin Cell Biol. 2014;28:61-8.

46. D'Angelo MA, Hetzer MW. Structure, dynamics and function of nuclear pore complexes. Trends Cell Biol. 2008;18:456-66

47. D'Angelo MA. Nuclear pore complexes as hubs for gene regulation. Nucleus. 2018;9:142-8. 
48. Brohawn SG, Partridge JR, Whittle JRR, Schwartz TU. The nuclear pore complex has entered the atomic age. Struct Lond Engl 1993. 2009;17:1156-68.

49. Paine PL. Nucleocytoplasmic movement of fluorescent tracers microinjected into living salivary gland cells. J Cell Biol. 1975;66:652-7.

50. Reichelt R, Holzenburg A, Buhle EL Jr, Jarnik M, Engel A, Aebi U. Correlation between structure and mass distribution of the nuclear pore complex and of distinct pore complex components. J Cell Biol. 1990;110:883-94.

51. Rout MP, Aitchison JD, Suprapto A, Hjertaas K, Zhao Y, Chait BT. The yeast nuclear pore complex: composition, architecture, and transport mechanism. J Cell Biol. 2000;148:635-51.

52. De Robertis EM, Longthorne RF, Gurdon JB. Intracellular migration of nuclear proteins in Xenopus oocytes. Nature. 1978;272:254-6.

53. Dingwall C, Sharnick SV, Laskey RA. A polypeptide domain that specifies migration of nucleoplasmin into the nucleus. Cell. 1982;30:449-58.

54. Hayama R, Rout MP, Fernandez-Martinez J. The nuclear pore complex core scaffold and permeability barrier: variations of a common theme. Curr Opin Cell Biol. 2017:46:110-8.

55. Suntharalingam M, Wente SR. Peering through the pore: nuclear pore complex structure, assembly, and function. Dev Cell. 2003;4:775-89.

56. Raveh B, Karp JM, Sparks S, Dutta K, Rout MP, Sali A, et al. Slide-andexchange mechanism for rapid and selective transport through the nuclear pore complex. Proc Natl Acad Sci. 2016;113:E2489-97.

57. Beck $M$, Hurt E. The nuclear pore complex: understanding its function through structural insight. Nat Rev Mol Cell Biol. 2017;18:73-89.

58. Zilman A. Aggregation, phase separation and spatial morphologies of the assemblies of FG nucleoporins. J Mol Biol. 2018;430:4730-40.

59. Panté N, Kann M. Nuclear pore complex is able to transport macromolecules with diameters of about $39 \mathrm{~nm}$. Mol Biol Cell. 2002;13:425-34.

60. Keminer O, Peters R. Permeability of single nuclear pores. Biophys J. 1999;77: 217-28.

61. Frey $\mathrm{S}$, Görlich D. A saturated FG-repeat hydrogel can reproduce the permeability properties of nuclear pore complexes. Cell. 2007;130:512-23.

62. Mohr D, Frey S, Fischer T, Güttler T, Görlich D. Characterisation of the passive permeability barrier of nuclear pore complexes. EMBO J. 2009;28:2541-53.

63. Jovanovic-Talisman T, Zilman A. Protein transport by the nuclear pore complex: simple biophysics of a complex biomachine. Biophys J. 2017;113:6-14.

64. Pemberton LF, Paschal BM. Mechanisms of receptor-mediated nuclear import and nuclear export. Traffic Cph Den. 2005:6:187-98.

65. Tran EJ, Wente SR. Dynamic nuclear pore complexes: life on the edge. Cell. 2006;125:1041-53.

66. Sorokin AV, Kim ER, Ovchinnikov LP. Nucleocytoplasmic transport of proteins. Biochem Biokhimiia. 2007;72:1439-57.

67. Fukuda M, Asano S, Nakamura T, Adachi M, Yoshida M, Yanagida M, et al. CRM1 is responsible for intracellular transport mediated by the nuclear export signal. Nature. 1997;390:308-11.

68. Görlich D, Panté N, Kutay U, Aebi U, Bischoff FR. Identification of different roles for RanGDP and RanGTP in nuclear protein import. EMBO J. 1996;15: 5584-94.

69. Bayliss R, Littlewood T, Strawn LA, Wente SR, Stewart M. GLFG and FxFG nucleoporins bind to overlapping sites on importin-beta. J Biol Chem. 2002; 277:50597-606.

70. Bayliss R, Leung SW, Baker RP, Quimby BB, Corbett AH, Stewart M. Structural basis for the interaction between NTF2 and nucleoporin FxFG repeats. EMBO J. 2002;21:2843-53.

71. Fu X, Liang C, Li F, Wang L, Wu X, Lu A, et al. The rules and functions of nucleocytoplasmic shuttling proteins. Int J Mol Sci. 2018;19:1445.

72. Moore MS. Nuclear pores: David and Goliath in nuclear transport. Curr Biol 1995;5:1339-41.

73. Izaurralde E, Kutay U, von Kobbe C, Mattaj IW, Görlich D. The asymmetric distribution of the constituents of the ran system is essential for transport into and out of the nucleus. EMBO J. 1997;16:6535-47.

74. Wen W, Meinkotht JL, Tsien RY, Taylor SS. Identification of a signal for rapid export of proteins from the nucleus. Cell. 1995:82:463-73.

75. Bischoff FR, Ponstingl $H$. Catalysis of guanine nucleotide exchange on Ran by the mitotic regulator RCC1. Nature. 1991;354:80-2.

76. la Cour T, Kiemer L, Mølgaard A, Gupta R, Skriver K, Brunak S. Analysis and prediction of leucine-rich nuclear export signals. Protein Eng Des Sel PEDS. 2004;17:527-36

77. Mahajan R, Delphin C, Guan T, Gerace L, Melchior F. A small ubiquitinrelated polypeptide involved in targeting RanGAP1 to nuclear pore complex protein RanBP2. Cell. 1997;88:97-107.
78. Taagepera S, McDonald D, Loeb JE, Whitaker LL, McElroy AK, Wang JY, et al. Nuclear-cytoplasmic shuttling of C-ABL tyrosine kinase. Proc Natl Acad Sci U S A. 1998:95:7457-62.

79. Paraskeva E, Izaurralde E, Bischoff FR, Huber J, Kutay U, Hartmann E, et al. CRM1-mediated recycling of snurportin 1 to the cytoplasm. J Cell Biol. 1999; 145:255-64.

80. Kubitscheck U, Siebrasse J-P. Kinetics of transport through the nuclear pore complex. Semin Cell Dev Biol. 2017;68:18-26.

81. Bourne HR, Sanders DA, McCormick F. The GTPase superfamily: conserved structure and molecular mechanism. Nature. 1991;349:117-27.

82. Kutay U, Lipowsky G, Izaurralde E, Bischoff FR, Schwarzmaier P, Hartmann E, et al. Identification of a tRNA-specific nuclear export receptor. Mol Cell. 1998;1:359-69.

83. Bohnsack MT, Czaplinski K, Gorlich D. Exportin 5 is a RanGTP-dependent dsRNA-binding protein that mediates nuclear export of pre-miRNAs. RNA N Y N. 2004;10:185-91

84. Arts GJ, Kuersten S, Romby P, Ehresmann B, Mattaj IW. The role of exportin-t in selective nuclear export of mature tRNAs. EMBO J. 1998;17:7430-41.

85. Kim VN. MicroRNA precursors in motion: exportin-5 mediates their nuclear export. Trends Cell Biol. 2004;14:156-9.

86. Okamura $\mathrm{M}$, Inose $\mathrm{H}$, Masuda S. RNA export through the NPC in eukaryotes. Genes. 2015;6:124-49.

87. Wickramasinghe VO, Laskey RA. Control of mammalian gene expression by selective mRNA export. Nat Rev Mol Cell Biol. 2015;16:431-42.

88. Strässer K, Masuda S, Mason P, Pfannstiel J, Oppizzi M, Rodriguez-Navarro S, et al. TREX is a conserved complex coupling transcription with messenger RNA export. Nature. 2002;417:304-8.

89. Hough LE, Dutta K, Sparks S, Temel DB, Kamal A, Tetenbaum-Novatt J, et al. The molecular mechanism of nuclear transport revealed by atomic-scale measurements. eLife. 2015; Available from: https://elifesciences.org/articles/1 0027. [cited 2018 Dec 31].

90. Lari A, Arul Nambi Rajan A, Sandhu R, Reiter T, Montpetit R, Young BP, et al. A nuclear role for the DEAD-box protein Dbp5 in tRNA export. eLife. 2019;8: e48410.

91. Swinnen B, Robberecht W. The phenotypic variability of amyotrophic lateral sclerosis. Nat Rev Neurol. 2014;10:661-70.

92. Lomen-Hoerth C, Anderson T, Miller B. The overlap of amyotrophic lateral sclerosis and frontotemporal dementia. Neurology. 2002;59:1077-9.

93. Hodges JR, Davies RR, Xuereb JH, Casey B, Broe M, Bak TH, et al. Clinicopathological correlates in frontotemporal dementia. Ann Neurol. 2004;56:399-406.

94. Mackenzie IRA, Neumann M. Molecular neuropathology of frontotemporal dementia: insights into disease mechanisms from postmortem studies. Neurochem. 2016;138(Suppl 1):54-70.

95. Ling S-C, Polymenidou M, Cleveland DW. Converging mechanisms in ALS and FTD: disrupted RNA and protein homeostasis. Neuron. 2013;79:416-38.

96. Barber SC, Shaw PJ. Oxidative stress in ALS: key role in motor neuron injury and therapeutic target. Free Radic Biol Med. 2010;48:629-41.

97. Buratti E, Brindisi A, Giombi M, Tisminetzky S, Ayala YM, Baralle FE. TDP-43 binds heterogeneous nuclear ribonucleoprotein $A / B$ through its $C$-terminal tail: an important region for the inhibition of cystic fibrosis transmembrane conductance regulator exon 9 splicing. J Biol Chem. 2005;280:37572-84.

98. Birsa N, Bentham MP, Fratta P. Cytoplasmic functions of TDP-43 and FUS and their role in ALS. Semin Cell Dev Biol. 2019.

99. Diaper DC, Adachi Y, Sutcliffe B, Humphrey DM, Elliott CJH, Stepto A, et al. Loss and gain of Drosophila TDP-43 impair synaptic efficacy and motor control leading to age-related neurodegeneration by loss-of-function phenotypes. Hum Mol Genet. 2013;22:1539-57.

100. Feiguin F, Godena VK, Romano G, D'Ambrogio A, Klima R, Baralle FE. Depletion of TDP-43 affects Drosophila motoneurons terminal synapsis and locomotive behavior. FEBS Lett. 2009;583:1586-92.

101. Ederle H, Funk C, Abou-Ajram C, Hutten S, Funk EBE, Kehlenbach RH, et al Nuclear egress of TDP-43 and FUS occurs independently of Exportin-1/ CRM1. Sci Rep. 2018;8 Available from: http://www.nature.com/articles/s415 98-018-25007-5. [cited 2018 Sep 16].

102. Archbold HC, Jackson KL, Arora A, Weskamp K, Tank EM-H, Li X, et al. TDP43 nuclear export and neurodegeneration in models of amyotrophic lateral sclerosis and frontotemporal dementia. Sci Rep. 2018:8 Available from: http://www.nature.com/articles/s41598-018-22858-w. [cited 2018 Sep 16].

103. Sugai A, Kato T, Koyama A, Koike $Y$, Kasahara S, Konno T, et al. Robustness and vulnerability of the autoregulatory system that maintains nuclear TDP- 
43 levels: a trade-off hypothesis for ALS pathology based on in silico data. Front Neurosci. 2018;12:28.

104. Xia Q, Wang G, Wang H, Hu Q, Ying Z. Folliculin, a tumor suppressor associated with Birt-Hogg-Dubé (BHD) syndrome, is a novel modifier of TDP-43 cytoplasmic translocation and aggregation. Hum Mol Genet. 2016; 25:83-96.

105. Nishimura AL, Zupunski V, Troakes C, Kathe C, Fratta P, Howell M, et al. Nuclear import impairment causes cytoplasmic trans-activation response DNA-binding protein accumulation and is associated with frontotemporal lobar degeneration. Brain I Neurol. 2010;133:1763-71.

106. Svahn AJ, Don EK, Badrock AP, Cole NJ, Graeber MB, Yerbury JJ, et al. Nucleo-cytoplasmic transport of TDP-43 studied in real time: impaired microglia function leads to axonal spreading of TDP-43 in degenerating motor neurons. Acta Neuropathol (Berl). 2018;136:445-59.

107. Aizawa H, Yamashita T, Kato H, Kimura T, Kwak S. Impaired nucleoporins are present in sporadic amyotrophic lateral sclerosis motor neurons that exhibit mislocalization of the 43-kDa TAR DNA-binding protein. J Clin Neurol Seoul Korea. 2019;15:62-7.

108. Gopal PP, Nirschl JJ, Klinman E, Holzbaur ELF. Amyotrophic lateral sclerosislinked mutations increase the viscosity of liquid-like TDP-43 RNP granules in neurons. Proc Natl Acad Sci U S A. 2017;114:E2466-75.

109. Solomon DA, Stepto A, Au WH, Adachi Y, Diaper DC, Hall R, et al. A feedback loop between dipeptide-repeat protein, TDP-43 and karyopherin-a mediates C9orf72-related neurodegeneration. Brain. 2018;141:2908-24.

110. Giampetruzzi A, Danielson EW, Gumina V, Jeon M, Boopathy S, Brown RH, et al. Modulation of actin polymerization affects nucleocytoplasmic transport in multiple forms of amyotrophic lateral sclerosis. Nat Commun. 2019;10:3827.

111. Shelkovnikova TA. Modelling FUSopathies: focus on protein aggregation. Biochem Soc Trans. 2013;41:1613-7.

112. Kwiatkowski TJ, Bosco DA, Leclerc AL, Tamrazian E, Vanderburg CR, Russ C, et al. Mutations in the FUS/TLS gene on chromosome 16 cause familial amyotrophic lateral sclerosis. Science. 2009;323:1205-8.

113. Kwong LK, Neumann M, Sampathu DM, Lee VM-Y, Trojanowski JQ. TDP-43 proteinopathy: the neuropathology underlying major forms of sporadic and familial frontotemporal lobar degeneration and motor neuron disease. Acta Neuropathol (Berl). 2007;114:63-70.

114. Sreedharan J, Blair IP, Tripathi VB, Hu X, Vance C, Rogelj B, et al. TDP-43 mutations in familial and sporadic amyotrophic lateral sclerosis. Science. 2008;319:1668-72.

115. Rogelj B, Easton LE, Bogu GK, Stanton LW, Rot G, Curk T, et al. Widespread binding of FUS along nascent RNA regulates alternative splicing in the brain. Sci Rep. 2012;2:603.

116. De Santis R, Santini L, Colantoni A, Peruzzi G, de Turris V, Alfano V, et al. FUS mutant human motoneurons display altered transcriptome and microRNA pathways with implications for ALS pathogenesis. Stem Cell Rep. 2017;9:1450-62.

117. Wang W-Y, Pan L, Su SC, Quinn EJ, Sasaki M, Jimenez JC, et al. Interaction of FUS and HDAC1 regulates DNA damage response and repair in neurons. Nat Neurosci. 2013;16:1383-91.

118. Rulten SL, Rotheray A, Green RL, Grundy GJ, Moore DAQ, Gómez-Herreros F, et al. PARP-1 dependent recruitment of the amyotrophic lateral sclerosisassociated protein FUS/TLS to sites of oxidative DNA damage. Nucleic Acids Res. 2014:42:307-14.

119. Brelstaff J, Lashley T, Holton JL, Lees AJ, Rossor MN, Bandopadhyay R, et al. Transportin 1: a marker of FTLD-FUS. Acta Neuropathol (Berl). 2011;122:591-600.

120. Darovic S, Prpar Mihevc S, Župunski V, Gunčar G, Štalekar M, Lee Y-B, et al. Phosphorylation of C-terminal tyrosine residue 526 in FUS impairs its nuclear import. J Cell Sci. 2015;128:4151-9.

121. Tischbein M, Baron DM, Lin Y-C, Gall KV, Landers JE, Fallini C, et al. The RNAbinding protein FUS/TLS undergoes calcium-mediated nuclear egress during excitotoxic stress and is required for GRIA2 mRNA processing. J Biol Chem. 2019;294:10194-210.

122. Bosco DA, Lemay N, Ko HK, Zhou H, Burke C, Kwiatkowski TJ, et al. Mutant FUS proteins that cause amyotrophic lateral sclerosis incorporate into stress granules. Hum Mol Genet. 2010;19:4160-75.

123. Dormann D, Madl T, Valori CF, Bentmann E, Tahirovic S, Abou-Airam C, et al. Arginine methylation next to the PY-NLS modulates Transportin binding and nuclear import of FUS. EMBO J. 2012;31:4258-75.

124. Qamar S, Wang G, Randle SJ, Ruggeri FS, Varela JA, Lin JQ, et al. FUS phase separation is modulated by a molecular chaperone and methylation of arginine cation- $\pi$ interactions. Cell. 2018;173:720-734.e15.
125. Hoch NC, Hanzlikova H, Rulten SL, Tétreault M, Komulainen E, Ju L, et al. XRCC1 mutation is associated with PARP1 hyperactivation and cerebellar ataxia. Nature. 2017:541:87-91.

126. Wang H, Guo W, Mitra J, Hegde PM, Vandoorne T, Eckelmann BJ, et al. Mutant FUS causes DNA ligation defects to inhibit oxidative damage repair in amyotrophic lateral sclerosis. Nat Commun. 2018:9:3683.

127. Naumann M, Pal A, Goswami A, Lojewski X, Japtok J, Vehlow A, et al. Impaired DNA damage response signaling by FUS-NLS mutations leads to neurodegeneration and FUS aggregate formation. Nat Commun. 2018;9 Available from: http://www.nature.com/articles/s41467-017-02299-1. [cited 2018 Sep 16]

128. Steyaert J, Scheveneels W, Vanneste J, Van Damme P, Robberecht W, Callaerts $P$, et al. FUS-induced neurotoxicity in Drosophila is prevented by downregulating nucleocytoplasmic transport proteins. Hum Mol Genet. 2018:27:4103-16.

129. DeJesus-Hernandez M, Mackenzie IR, Boeve BF, Boxer AL, Baker M, Rutherford NJ, et al. Expanded GGGGCC hexanucleotide repeat in noncoding region of C9ORF72 causes chromosome 9p-linked FTD and ALS. Neuron. 2011;72:245-56

130. Renton AE, Majounie E, Waite A, Simón-Sánchez J, Rollinson S, Gibbs JR, et al. A hexanucleotide repeat expansion in C9ORF72 is the cause of chromosome 9p21-linked ALS-FTD. Neuron. 2011;72:257-68.

131. Yuva-Aydemir Y, Almeida S, Gao F-B. Insights into C9ORF72 -related ALS/ FTD from drosophila and iPSC models. Trends Neurosci. 2018;41:457-69.

132. Babić Leko M, Župunski V, Kirincich J, Smilović D, Hortobágyi T, Hof PR, et al. Molecular mechanisms of neurodegeneration related to C9orf72 hexanucleotide repeat expansion. Behav Neurol. 2019;2019 Available from: https:/www.ncbi.nlm.nih.gov/pmc/articles/PMC6350563/. [cited 2020 Feb 8].

133. Burberry A, Suzuki N, Wang J-Y, Moccia R, Mordes DA, Stewart MH, et al. Loss-of-function mutations in the C9ORF72 mouse ortholog cause fatal autoimmune disease. Sci Transl Med. 2016;8:347ra93.

134. Xiao S, MacNair L, McGoldrick P, McKeever PM, McLean JR, Zhang M, et al. Isoform-specific antibodies reveal distinct subcellular localizations of C9orf72 in amyotrophic lateral sclerosis. Ann Neurol. 2015;78:568-83.

135. C9orf72 is required for proper macrophage and microglial function in mice | Science [Internet]. Available from: http://science.sciencemag.org/ content/351/6279/1324. [cited 2018 Dec 1].

136. Giijselinck I, Van Langenhove T, van der Zee J, Sleegers K, Philtjens S, Kleinberger $\mathrm{G}$, et al. A C9orf72 promoter repeat expansion in a FlandersBelgian cohort with disorders of the frontotemporal lobar degenerationamyotrophic lateral sclerosis spectrum: a gene identification study. Lancet Neurol. 2012;11:54-65.

137. Mohan A, Goodwin M, Swanson MS. RNA-protein interactions in unstable microsatellite diseases. Brain Res. 2014;1584:3-14.

138. Haeusler AR, Donnelly CJ, Periz G, Simko EAJ, Shaw PG, Kim M-S, et al. C9orf72 nucleotide repeat structures initiate molecular cascades of disease. Nature. 2014;507:195-200.

139. O'Rourke JG, Bogdanik L, Muhammad AKMG, Gendron TF, Kim KJ, Austin A, et al. C9orf72 BAC transgenic mice display typical pathologic features of ALS/FTD. Neuron. 2015;88:892-901.

140. Zu T, Gibbens B, Doty NS, Gomes-Pereira M, Huguet A, Stone MD, et al. Non-ATG-initiated translation directed by microsatellite expansions. Proc Natl Acad Sci. 2011;108:260-5.

141. Chai N, Gitler AD. Yeast screen for modifiers of C9orf72 poly(glycinearginine) dipeptide repeat toxicity. FEMS Yeast Res. 2018;18 Available from: https://academic.oup.com/femsyr/article/doi/10.1093/femsyr/foy024/4925 064. [cited 2018 Sep 16].

142. Zu T, Liu Y, Bañez-Coronel M, Reid T, Pletnikova O, Lewis J, et al. RAN proteins and RNA foci from antisense transcripts in C9ORF72 ALS and frontotemporal dementia. Proc Natl Acad Sci. 2013;110:E4968-77.

143. Donnelly CJ, Zhang P-W, Pham JT, Haeusler AR, Mistry NA, Vidensky S, et al. RNA toxicity from the ALS/FTD C9ORF72 expansion is mitigated by antisense intervention. Neuron. 2013;80:415-28.

144. Targeting RNA Foci in IPSC-Derived Motor Neurons from ALS Patients with a C9ORF72 Repeat Expansion | Science Translational Medicine [Internet]. Available from: http://stm.sciencemag.org/content/5/208/208ra149. [cited 2018 Dec 1].

145. Almeida S, Gascon E, Tran H, Chou HJ, Gendron TF, DeGroot S, et al. Modeling key pathological features of frontotemporal dementia with C9ORF72 repeat expansion in IPSC-derived human neurons. Acta Neuropathol (Berl). 2013;126:385-99. 
146. Liu Y, Pattamatta A, Zu T, Reid T, Bardhi O, Borchelt DR, et al. C9orf72 BAC mouse model with motor deficits and neurodegenerative features of ALS/ FTD. Neuron. 2016;90:521-34

147. Jiang J, Zhu Q, Gendron TF, Saberi S, McAlonis-Downes M, Seelman A, et al. Gain of toxicity from ALS/FTD-linked repeat expansions in C9ORF72 is alleviated by antisense oligonucleotides targeting GGGGCC-containing RNAs. Neuron. 2016;90:535-50.

148. Mizielinska S, Grönke S, Niccoli T, Ridler CE, Clayton EL, Devoy A, et al. C9orf72 repeat expansions cause neurodegeneration in drosophila through arginine-rich proteins. Science. 2014;345:1192-4.

149. Boeynaems S, Bogaert E, Michiels E, Gijselinck I, Sieben A, Jovičić A, et al. Drosophila screen connects nuclear transport genes to DPR pathology in C9ALS/FTD. Sci Rep. 2016;6:20877.

150. Jovičić A, Mertens J, Boeynaems S, Bogaert E, Chai N, Yamada SB, et al. Modifiers of C9orf72 dipeptide repeat toxicity connect nucleocytoplasmic transport defects to FTD/ALS. Nat Neurosci. 2015;18:1226-9.

151. Lin Y, Mori E, Kato M, Xiang S, Wu L, Kwon I, et al. Toxic PR poly-dipeptides encoded by the C9orf72 repeat expansion target LC domain polymers. Cell. 2016;167:789-802.e12.

152. Lee K-H, Zhang P, Kim HJ, Mitrea DM, Sarkar M, Freibaum BD, et al. C9orf72 dipeptide repeats impair the assembly, dynamics, and function of membrane-less organelles. Cell. 2016;167:774-788.e17.

153. Freibaum BD, Lu Y, Lopez-Gonzalez R, Kim NC, Almeida S, Lee K-H, et al. GGGGCC repeat expansion in C9orf72 compromises nucleocytoplasmic transport. Nature. 2015;525:129-33.

154. Zhang K, Donnelly CJ, Haeusler AR, Grima JC, Machamer JB, Steinwald P, et al. The C9orf72 repeat expansion disrupts nucleocytoplasmic transport. Nature. 2015;525:56-61.

155. Moore S, Alsop E, Lorenzini I, Starr A, Rabichow BE, Mendez E, et al. ADAR2 mislocalization and widespread RNA editing aberrations in C9orf72mediated ALS/FTD. Acta Neuropathol (Berl). 2019;138:49-65.

156. Rosen DR, Siddique T, Patterson D, Figlewicz DA, Sapp P, Hentati A, et al Mutations in $\mathrm{Cu} / \mathrm{Zn}$ superoxide dismutase gene are associated with familial amyotrophic lateral sclerosis. Nature. 1993;362:59-62.

157. Chang Y, Kong Q, Shan X, Tian G, Ilieva H, Cleveland DW, et al. Messenger RNA oxidation occurs early in disease pathogenesis and promotes motor neuron degeneration in ALS. PLoS One. 2008;3:e2849.

158. Zhang J, Ito H, Wate R, Ohnishi S, Nakano S, Kusaka H. Altered distributions of nucleocytoplasmic transport-related proteins in the spinal cord of a mouse model of amyotrophic lateral sclerosis. Acta Neuropathol (Berl). 2006; 112:673-80.

159. Kinoshita $Y$, Ito $H$, Hirano A, Fujita K, Wate R, Nakamura M, et al. Nuclear contour irregularity and abnormal transporter protein distribution in anterior horn cells in amyotrophic lateral sclerosis. J Neuropathol Exp Neurol. 2009;68:1184-92.

160. al A-RA et. Inositol hexakisphosphate and Gle1 activate the DEAD-box protein Dbp5 for nuclear mRNA export. - PubMed - NCBI [Internet]. [cited 2018 Dec 2]. Available from: https://www.ncbi.nlm.nih.gov/pubmed/16 783363

161. Nousiainen HO, Kestilä M, Pakkasjärvi N, Honkala H, Kuure S, Tallila J, et al. Mutations in mRNA export mediator GLE1 result in a fetal motoneuron disease. Nat Genet. 2008;40:155-7.

162. Kaneb HM, Folkmann AW, Belzil W, Jao L-E, Leblond CS, Girard SL, et al. Deleterious mutations in the essential mRNA metabolism factor, hGle1, in amyotrophic lateral sclerosis. Hum Mol Genet. 2015;24:1363-73.

163. Folkmann AW, Collier SE, Zhan X, Null A, Ohi MD, Wente SR. Gle1 functions during $\mathrm{mRNA}$ export in an oligomeric complex that is altered in human disease. Cell. 2013;155:582-93.

164. Hautbergue GM. RNA nuclear export: from neurological disorders to cancer. In: El-Khamisy S, editor. Pers Med. Cham: Springer International Publishing; 2017. p. 89-109. Available from: http://link.springer.com/10.1007/978-3-319-6 0733-7_6. [cited 2018 Sep 16].

165. Landles C, Bates GP. Huntingtin and the molecular pathogenesis of Huntington's disease. EMBO Rep. 2004:5:958-63.

166. Jimenez-Sanchez M, Licitra F, Underwood BR, Rubinsztein DC. Huntington's disease: mechanisms of pathogenesis and therapeutic strategies. Cold Spring Harb Perspect Med. 2017;7.

167. Maiuri T, Woloshansky T, Xia J, Truant R. The huntingtin N17 domain is a multifunctional CRM1 and Ran-dependent nuclear and cilial export signal. Hum Mol Genet. 2013:22:1383-94.
168. Polyglutamine-expanded huntingtin exacerbates age-related disruption of nuclear integrity and nucleocytoplasmic transport - ScienceDirect [Internet]. Available from: https://www.sciencedirect.com/science/article/pii/S089662 7317302398. [cited 2018 Dec 2].

169. Kumar A, Ratan RR. Oxidative stress and Huntington's disease: the good, the bad, and the ugly. J Huntingt Dis. 2016;5:217-37.

170. Bañez-Coronel M, Ayhan F, Tarabochia AD, Zu T, Perez BA, Tusi SK, et al. RAN translation in Huntington disease. Neuron. 2015;88:667-77.

171. Manto M-U. The wide spectrum of spinocerebellar ataxias (SCAs). Cerebellum. 2005;4:2.

172. Sowa AS, Martin E, Martins IM, Schmidt J, Depping R, Weber JJ, et al. Karyopherin a-3 is a key protein in the pathogenesis of spinocerebellar ataxia type 3 controlling the nuclear localization of ataxin-3. Proc Natl Acad Sci. 2018;115:E2624-33.

173. Bennett CL, Dastidar SG, Ling S-C, Malik B, Ashe T, Wadhwa M, et al. Senataxin mutations elicit motor neuron degeneration phenotypes and yield TDP-43 mislocalization in ALS4 mice and human patients. Acta Neuropathol (Berl). 2018;136:425-43.

174. Nguyen L, Cleary JD, Ranum LPW. Repeat associated non-ATG translation: molecular mechanisms and contribution to neurologic disease. Annu Rev Neurosci. 2019:42:227-47.

175. Hagerman R, Hagerman P. Advances in clinical and molecular understanding of the FMR1 premutation and fragile X-associated tremor/ ataxia syndrome. Lancet Neurol. 2013;12:786-98.

176. Cohen S, Masyn K, Adams J, Hessl D, Rivera S, Tassone F, et al. Molecular and imaging correlates of the fragile $\mathrm{X}$-associated tremor/ataxia syndrome. Neurology. 2006;67:1426-31.

177. Edens BM, Vissers C, Su J, Arumugam S, Xu Z, Shi H, et al. FMRP modulates neural differentiation through m6A-dependent mRNA nuclear export. Cell Rep. 2019;28:845-854.e5.

178. Arnold FJ, Pluciennik A, Merry DE. Impaired nuclear export of polyglutamine-expanded androgen receptor in spinal and bulbar muscular atrophy. Sci Rep. 2019;9 Available from: https://www.ncbi.nlm.nih.gov/pmc/ articles/PMC6333819/. [cited 2020 Feb 6].

179. Nagafuchi S, Yanagisawa H, Ohsaki E, Shirayama T, Tadokoro K, Inoue T, et al. Structure and expression of the gene responsible for the triplet repeat disorder, dentatorubral and pallidoluysian atrophy (DRPLA). Nat Genet. 1994; 8:177-82.

180. Takahashi H, Egawa S, Piao YS, Hayashi S, Yamada M, Shimohata T, et al. Neuronal nuclear alterations in dentatorubral-pallidoluysian atrophy: ultrastructural and morphometric studies of the cerebellar granule cells. Brain Res. 2001;919:12-9.

181. Moreira M-C, Klur S, Watanabe M, Németh AH, Ber IL, Moniz J-C, et al. Senataxin, the ortholog of a yeast RNA helicase, is mutant in ataxia-ocular apraxia 2. Nat Genet. 2004:36:225-7.

182. Hirano M, Quinzii CM, Mitsumoto H, Hays AP, Roberts JK, Richard P, et al. Senataxin mutations and amyotrophic lateral sclerosis. Amyotroph Lateral Scler Off Publ World Fed Neurol Res Group Mot Neuron Dis. 2011;12:223-7.

183. Moreira M-C, Barbot C, Tachi N, Kozuka N, Uchida E, Gibson T, et al. The gene mutated in ataxia-ocular apraxia 1 encodes the new HIT/Zn-finger protein aprataxin. Nat Genet. 2001;29:189-93.

184. Hirano M, Furiya Y, Asai H, Yasui A, Ueno S. ALADINI482S causes selective failure of nuclear protein import and hypersensitivity to oxidative stress in triple a syndrome. Proc Natl Acad Sci. 2006;103:2298-303.

185. Zanni G, De Magistris P, Nardella M, Bellacchio E, Barresi S, Sferra A, et al. Biallelic variants in the nuclear pore complex protein NUP93 are associated with non-progressive congenital ataxia. Cerebellum Lond Engl. 2019;18:422-32

186. Lotharius J, Brundin P. Pathogenesis of Parkinson's disease: dopamine, vesicles and a-synuclein. Nat Rev Neurosci. 2002;3:932-42.

187. Pinho R, Paiva I, Jercic KG, Fonseca-Ornelas L, Gerhardt E, Fahlbusch C, et al. Nuclear localization and phosphorylation modulate pathological effects of alpha-synuclein. Hum Mol Genet. 2019;28:31-50.

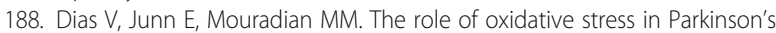
disease. J Park Dis. 2013:3:461-91.

189. Hunot S, Brugg B, Ricard D, Michel PP, Muriel M-P, Ruberg M, et al. Nuclear translocation of NF-KB is increased in dopaminergic neurons of patients with Parkinson disease. Proc Natl Acad Sci U S A. 1997;94:7531-6.

190. Chalovich EM, Zhu J, Caltagarone J, Bowser R, Chu CT. Functional repression of CAMP response element in 6-hydroxydopamine-treated neuronal cells. J Biol Chem. 2006:281:17870-81. 
191. Um JW, Min DS, Rhim H, Kim J, Paik SR, Chung KC. Parkin ubiquitinates and promotes the degradation of RanBP2. J Biol Chem. 2006;281:3595-603.

192. Petrucelli L, O'Farrell C, Lockhart PJ, Baptista M, Kehoe K, Vink L, et al. Parkin protects against the toxicity associated with mutant a-Synuclein: proteasome dysfunction selectively affects catecholaminergic neurons. Neuron. 2002:36:1007-19.

193. Beyer K, Domingo-Sàbat M, Humbert J, Carrato C, Ferrer I, Ariza A. Differential expression of alpha-synuclein, parkin, and synphilin-1 isoforms in Lewy body disease. Neurogenetics. 2008;9:163-72.

194. Dawson TM. Parkin and defective ubiquitination in Parkinson's disease. In: Riederer P, Reichmann H, Youdim MBH, Gerlach M, editors. Park Dis Relat Disord. Vienna: Springer; 2006. p. 209-13.

195. Langston JW. The MPTP story. J Park Dis. 2017;7:S11-9.

196. Cho K-I, Searle K, Webb M, Yi H, Ferreira PA. Ranbp2 haploinsufficiency mediates distinct cellular and biochemical phenotypes in brain and retinal dopaminergic and glia cells elicited by the parkinsonian neurotoxin, 1 methyl-4-phenyl-1,2,3,6-tetrahydropyridine (MPTP). Cell Mol Life Sci CMLS. 2012;69:3511-27.

197. Scheltens P, Blennow K, Breteler MMB, de Strooper B, Frisoni GB, Salloway S, et al. Alzheimer's disease. Lancet. 2016;388:505-17.

198. Metuzals J, Robitaille Y, Houghton S, Gauthier S, Leblanc R. Paired helica filaments and the cytoplasmic-nuclear interface in Alzheimer's disease. J Neurocytol. 1988;17:827-33.

199. Mulvihill P, Perry G. Immunoaffinity demonstration that paired helical filaments of Alzheimer disease share epitopes with neurofilaments, MAP2 and tau. Brain Res. 1989;484:150-6.

200. Sheffield LG, Miskiewicz HB, Tannenbaum LB, Mirra SS. Nuclear pore complex proteins in Alzheimer disease. J Neuropathol Exp Neurol. 2006;65:45-54.

201. Mastroeni D, Chouliaras L, Grover A, Liang WS, Hauns K, Rogers J, et al. Reduced RAN expression and disrupted transport between cytoplasm and nucleus; A Key Event in Alzheimer's Disease Pathophysiology. PLoS One. 2013;8:e53349.

202. Tripathi T, Kalita J. Abnormal microtubule dynamics impair the nuclearcytoplasmic transport in dementia. ACS Chem Neurosci. 2019;10:1133-4.

203. Paonessa F, Evans LD, Solanki R, Larrieu D, Wray S, Hardy J, et al. Microtubules deform the nuclear membrane and disrupt nucleocytoplasmic transport in Tau-mediated frontotemporal dementia. Cell Rep. 2019;26:582-593.e5.

204. Montalbano M, McAllen S, Sengupta U, Puangmalai N, Bhatt N, Ellsworth A, et al. Tau oligomers mediate aggregation of RNA-binding proteins Musashi1 and Musashi2 inducing Lamin alteration. Aging Cell. 2019;18 Available from: https:/www.ncbi.nlm.nih.gov/pmc/articles/PMC6826126/. [cited 2020 Feb 6].

205. Allgrove J, Clayden GS, Grant DB, Macaulay JC. Familial glucocorticoid deficiency with achalasia of the cardia and deficient tear production. Lancet Lond Engl. 1978;1:1284-6.

206. Prasad R, Metherell LA, Clark AJ, Storr HL. Deficiency of ALADIN impairs redox homeostasis in human adrenal cells and inhibits steroidogenesis. Endocrinology. 2013;154:3209-18.

207. Bitetto G, Ronchi D, Bonato S, Pittaro A, Compagnoni GM, Bordoni A, et al. Loss of the nucleoporin Aladin in central nervous system and fibroblasts of Allgrove syndrome. Hum Mol Genet. 2019. https://doi.org/10.1093/hmg/ ddz236.

208. Liguori I, Russo G, Curcio F, Bulli G, Aran L, Della-Morte D, et al. Oxidative stress, aging, and diseases. Clin Interv Aging. 2018;13:757-72.

209. Wang X, Michaelis EK. Selective neuronal vulnerability to oxidative stress in the brain. Front Aging Neurosci. 2010;2 Available from: https://www. frontiersin.org/articles/10.3389/fnagi.2010.00012/full. [cited 2020 Feb 7].

210. Beckman KB, Ames BN. The free radical theory of aging matures. Physiol Rev. 1998;78:547-81.

211. Chandrasekaran A, Idelchik MDPS, Melendez JA. Redox control of senescence and age-related disease. Redox Biol. 2017;11:91-102

212. Ferri G, Storti B, Bizzarri R. Nucleocytoplasmic transport in cells with progerin-induced defective nuclear lamina. Biophys Chem. 2017:229:77-83.

213. Dworak N, Makosa D, Chatterjee M, Jividen K, Yang C-S, Snow C, et al. A nuclear lamina-chromatin-Ran GTPase axis modulates nuclear import and DNA damage signaling. Aging Cell. 2019;18:e12851.

214. Fifková E, Tonks M, Cullen-Dockstader K. Changes in the nuclear pore complexes of the dentate granule cells in aged rats. Exp Neurol. 1987;95: 755-62

215. D'Angelo MA, Raices M, Panowski SH, Hetzer MW. Age-dependent deterioration of nuclear pore complexes causes a loss of nuclear integrity in postmitotic cells. Cell. 2009;136:284-95.
216. Toyama BH, Savas JN, Park SK, Harris MS, Ingolia NT, Yates JR, et al. Identification of long-lived proteins reveals exceptional stability of essential cellular structures. Cell. 2013;154:971-82.

217. Mertens J, Paquola ACM, Ku M, Hatch E, Böhnke L, Ladjevardi S, et al. Directly reprogrammed human neurons retain aging-associated transcriptomic signatures and reveal age-related nucleocytoplasmic defects. Cell Stem Cell. 2015;17:705-18.
Ready to submit your research? Choose BMC and benefit from:

- fast, convenient online submission

- thorough peer review by experienced researchers in your field

- rapid publication on acceptance

- support for research data, including large and complex data types

- gold Open Access which fosters wider collaboration and increased citations

- maximum visibility for your research: over $100 \mathrm{M}$ website views per year

At $\mathrm{BMC}$, research is always in progress.

Learn more biomedcentral.com/submissions 